\title{
Tejiendo relaciones a través de la cerámica en los primeros momentos de la era en la puna meridional argentina
}

\author{
Weaving relations through ceramics in the first moments \\ of the Era in the Southern Puna of Argentina
}

\author{
Leticia I. Gasparotti ${ }^{1}$ ORCID 0000-0001-9330-5871 \\ Patricia S. Escola ${ }^{2} \dagger$ ORCID 0000-0001-9034-973X \\ ${ }^{1}$ Centro de Investigación y Transferencia Catamarca - Universidad Nacional de Catamarca - \\ CONICET, ARGENTINA. Email: lgasparotti@arqueo.unca.edu.ar \\ ${ }^{2}$ Centro de Investigación y Transferencia Catamarca - Universidad Nacional de Catamarca - \\ CONICET, ARGENTINA. Email: patoescola@hotmail.com
}

\begin{abstract}
Resumen
Se presentan los resultados obtenidos del análisis del material cerámico proveniente del sitio Las Escondidas (quebrada de Miriguaca, puna meridional argentina) con el objetivo de abordar las características de la producción cerámica de los primeros momentos del Formativo (entre ca. 2000 AP y 1700 AP), para así tratar de indagar en el contexto social en el que esta cerámica fue producida y usada. Para ello se proponen dos etapas de análisis, la primera a través del uso de lupa binocular y la segunda, mediante análisis petrográficos.

Los resultados obtenidos permitieron establecer las características y la posible funcionalidad del repertorio cerámico, además de lograr determinar la composición de las pastas. Se identificaron ciertas elecciones tecnológicas constantes y una importante homogeneidad en el uso de materias primas específicas, que no han podido ser correlacionadas directamente con el entorno geológico local. Posteriormente, a partir de la detallada descripción petrográfica, se pudo comparar este conjunto con otros analizados previamente, tanto de la puna meridional argentina como de otros sectores circundantes, contribuyendo a establecer redes de relaciones en las cuales los objetos se vieron inmersos en los primeros momentos de la era.
\end{abstract}

Palabras claves: Antofagasta de la Sierra, petrografía, formativo, agropastoriles.

\begin{abstract}
The results obtained from the analysis of the ceramic material from the Las Escondidas site (Miriguaca grove, Southern Puna Argentina) are presented with the objective of addressing the characteristics of the ceramic production of the first moments of the Formative (between ca. $2000 \mathrm{AP}$ and $1700 \mathrm{AP}$ ), in order to investigate the social context in which this ceramic was produced and used. To do this, two stages of analysis are proposed, the first through the use of binocular magnifying glass and the second, through petrographic analysis.

The results obtained allowed to establish the particular characteristics and the possible functionality of the ceramic repertoire, as well as to determine the composition of the pastes. We identified certain constant technological choices and an important homogeneity in the use of specific raw materials, which could not be correlated directly with the local geological environment. Subsequently, from the detailed petrographic description, this set could be compared with others previously analyzed, both from the southern Puna of Argentina and from other surrounding sectors, contributing to establish networks of relationships in which the objects were immersed in the first moments of the era.
\end{abstract}

Keywords: Antofagasta de la Sierra, petrography, formative, agropastoralists.

Recibido: 9 junio 2018. Aceptado: 20 marzo 2019 


\section{Introducción}

Situada en la puna meridional argentina, la microrregión ${ }^{1}$ (sensu Aschero, 1988, p. 23) de Antofagasta de la Sierra ha sido objeto de investigaciones arqueológicas desde hace largo tiempo (Ambrosetti, 1904; Weiser, 1923; Krapovickas, 1955; Raffino y Cigliano, 1973, entre otros). Estas investigaciones han dado cuenta de una larga secuencia de ocupación humana que se remonta, por lo menos, hacia unos 10 mil años atrás (Elkin, 1996; Aschero y Martínez, 2001). Alrededor de 2 mil años AP los grupos humanos habrían adoptado un mayor grado de sedentarismo, teniendo control efectivo sobre la disponibilidad de recursos, e implementando prácticas agropastoriles complementadas por la caza y la recolección (Olivera, 1997, 2001; Escola, 2000). Es a este tipo de sociedades que se las ha denominado "Formativas" (sensu Korstanje, 2005; Olivera, 2012). ${ }^{2}$

Para Antofagasta de la Sierra, la dinámica social de este momento fue abordada a través del modelo de "sedentarismo dinámico" propuesto por Olivera (1986, 1988, 1991, 1992, entre otros). Así, se planteó que los grupos humanos de la Puna meridional habrían implementado una economía agropastoril con énfasis en el pastoreo de camélidos, complementado con la caza y la recolección, lo cual implicaría formas de asentamiento con un alto grado de sedentarismo (Olivera, 1986, 1988, 1992; Escola, 2000).

Partiendo de estas ideas, se propuso la existencia de un sistema logístico con un grado variable de

1 Definida como "una serie de microambientes o zonas con recursos topográficos y vegetales diferenciados que se presentan en una cierta continuidad espacial y que representan una muestra adecuada del potencial de recursos que ofrece la región geográfica en estudio". Cabe destacar que dicha definición puede hacerse extensiva a todo tipo de recursos naturales (faunísticos, minerales, etc.).

2 El término Formativo se utiliza en este trabajo para hacer referencia a un tipo de sociedad que posee un conjunto de características determinadas, no con una connotación cronológica. Estas sociedades tendrían como principal característica una vida sedentaria en aldeas, tecnologías básicas de uso diario, como la cerámica, y el desarrollo de técnicas agrarias. movilidad, lo cual conllevaría que los pobladores explotaran distintos microambientes (Olivera 1992; Escola, López Campeny, Martel, Romano, Hocsman, y Somonte, 2013) ${ }^{3}$ con ofertas diferenciales de recursos, accediendo a ellos ya sea en forma directa y periódica, o indirecta mediante estrategias de complementariedad o intercambio (Escola, 2000).

Fue a partir de este modelo, e intentando contrastarlo, que se realizaron investigaciones en el sector de fondo de cuenca, específicamente en el sitio Casa Chávez Montículos (Olivera, 1986, 1988, 1992; Escola, 2000). Este sitio fue catalogado como una aldea o base residencial habitada recurrentemente entre los 2.100 y 1.500 ańos AP aprox.

A pesar de que estos trabajos aportaron valiosa información al conocimiento del Formativo en Antofagasta de la Sierra, el panorama no estaba completo, ya que no existían investigaciones en otros sectores de la microrregión. Así, el sitio Las Escondidas se presenta como una oportunidad relevante para abordar la complejidad de este momento, sumando

3 Dentro de la microrregión, se definieron tres sectores microambientales, que se diferencian en cuanto a sus características ecológicas y topográficas así como también en lo que refiere a la oferta de recursos faunísticos, vegetales y minerales:

Fondo de cuenca, entre los 3.400 y $3.550 \mathrm{msnm}$, con vegetación de vega, tolar y campo. Este sector brinda las mejores posibilidades para la agricultura, ya que su topografía abierta y la disponibilidad de agua permanente permiten la existencia de suelos aptos. Por otra parte, los recursos animales registrados son Lama glama, Rea sp., Ctenomys sp. y aves acuáticas.

Sectores intermedios, entre los 3.550 y $3.800 \mathrm{msnm}$. Predominan las vegas, el tolar y el campo. Los sectores de quebradas con vegas son los más aptos para la producción agrícola en baja escala y pastoril. Los recursos animales registrados son Lama glama, Rea sp., Lagidium sp., Ctenomys sp. y aves. Cabe aclarar que los cursos inferiores de los ríos Las Pitas y Miriguaca son considerados parte de estos, a pesar de registrar una altitud de $3.400 \mathrm{msnm}$.

Quebradas de altura, entre los 3.800 y 4.600 msnm. Se conforman en los cursos medios y superiores de los ríos tributarios. Son, en general, quebradas relativamente estrechas y protegidas, donde corren cursos de agua permanentes. Aquí se registra vegetación de vega y pajonal, y recursos animales como Lama glama, Vicugna vicugna, Lagidium sp., otros roedores y aves. Son lugares principalmente aptos para el pastoreo. 
nueva información desde los sectores intermedios de las quebradas.

De este modo, el objetivo del presente trabajo es, en un nivel general, aportar nuevos datos al conocimiento del contexto del Formativo en la puna meridional, y más particularmente, alcanzar una mejor comprensión de las características de la ocupación de Las Escondidas a través del estudio del conjunto cerámico. Por otra parte, estudiar en profundidad el tipo de cerámica característico de Las Escondidas resulta de suma relevancia, ya que refiere a un estilo que podría ser considerado como específico de la puna, lo cual implicaría posiblemente cuestiones identitarias y de la propia dinámica social del momento.

\section{Localización y características del sitio Las Escondidas}

La puna constituye la terminación austral de la alta plataforma de los Andes centrales, mejor conocida a escala continental como altiplano, y puede ser considerada como un ambiente con una alta heteroge- neidad (Grana, 2013), a pesar de la cual es posible identificar ciertos rasgos generales. $\mathrm{Al}$ respecto, se puede destacar que la región puneña es desértica, de clima riguroso, con temperaturas invernales extremas, en la que, desde el punto de vista paisajístico, sobresalen extensas planicies, salinas e imponentes estratovolcanes que a veces sobrepasan los $6.000 \mathrm{~m}$ de altitud (Alonso y Viramonte, 1987).

Específicamente, la microrregión de Antofagasta de la Sierra se encuentra localizada en el sector noroeste de la Provincia de Catamarca (Argentina) formando parte de la puna meridional argentina. Se conforma sobre la base de la red hidrográfica endorreica de la cuenca del río Punilla, la más importante de la zona, alimentada y regulada por vertientes de régimen permanente, cuyas aguas provienen de las precipitaciones ocurridas en los cordones montañosos circundantes. Entre sus tributarios se encuentran los ríos Miriguaca, Las Pitas, Toconquis y el arroyo de Curuto, entre otros. Son ríos de agua permanente con escasa variación en sus caudales a lo largo del año (Olivera, Tchilinguirian y Grana, 2004; Tchilinguirian y Olivera, 2010) (Figura 1).

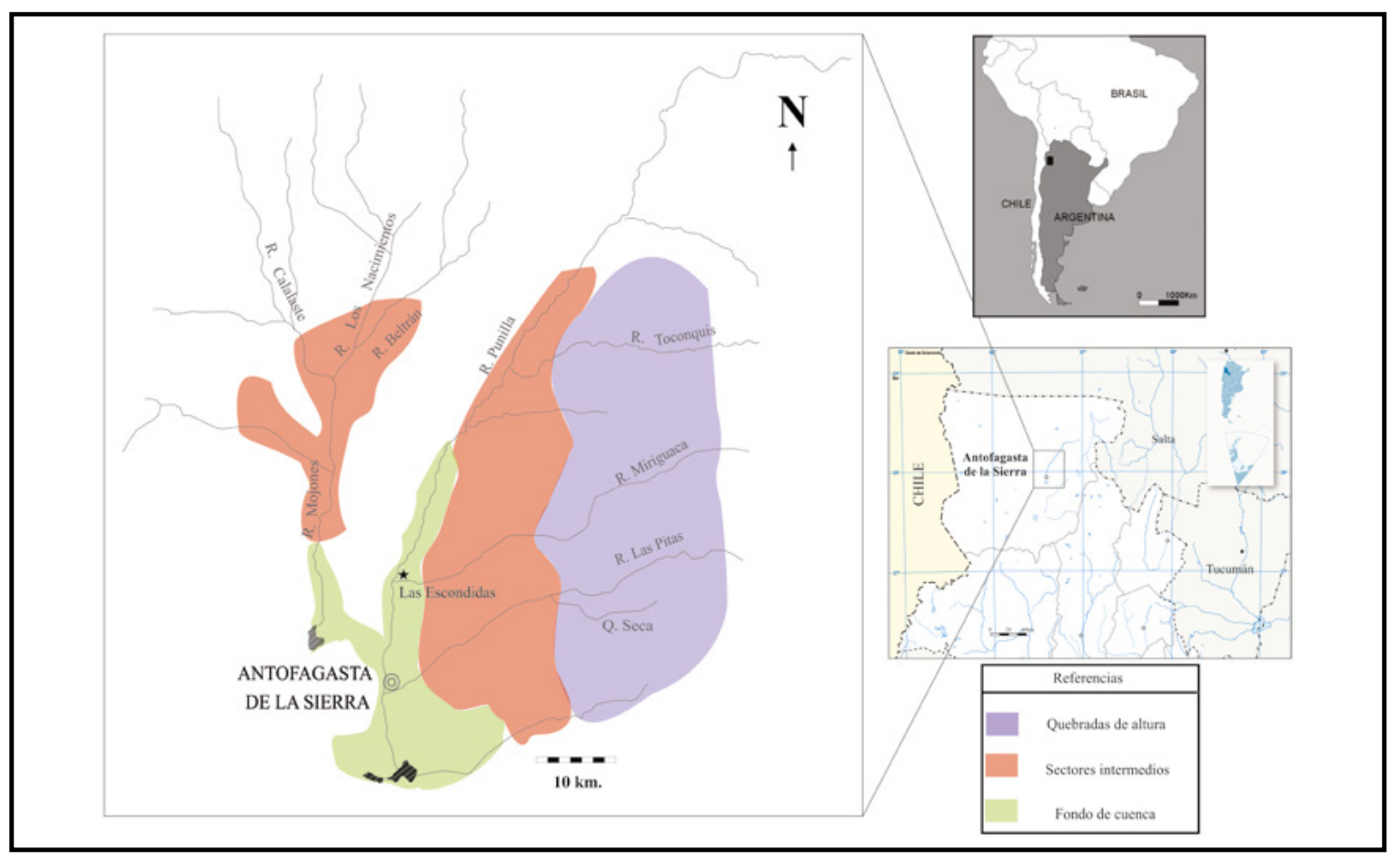

Figura 1. Localización de Las Escondidas. 
En el curso inferior del río Miriguaca se encuentra localizado el sitio Las Escondidas. A $3.517 \mathrm{msnm}$, en un nivel aterrazado sobre la margen derecha del río, se sitúan al menos seis estructuras de planta subcircular de grandes dimensiones. La disposición de las estructuras en el espacio es dispersa y abarca una amplia área de alrededor de $500 \mathrm{~m}^{2}$ (Figura 2) (Escola et al., 2013).

A simple vista, en la superficie del terreno, las estructuras pueden ser identificadas como una concentración de clastos de diversos tamaños. Dichas estructuras (E1, E2, E3, E4, E5 y E6) pueden variar entre $18 \mathrm{~m}$ de diámetro, como en el caso de la E4 que es la de mayor extensión, y $9 \mathrm{~m}$ de diámetro aproximadamente para las de menor superficie (Figura 2).

Además de las estructuras de grandes dimensiones, se registró también una variedad de recintos de menor tamaño. Algunos, de alrededor de $2 \mathrm{~m}$ de diámetro máximo aproximado, se ubican en el interior de los grandes círculos (como en los casos de las Estructuras E4 y E1), o en situación perimetral, adosados a los muros (como en la Estructura E2).

Asimismo, recientemente pudieron ser identificados dos recintos de dimensiones intermedias $(7 \mathrm{~m}$ de diámetro máximo), con una conformación mucho menos definida que los anteriores, y casi completamente colmatados por sedimentos. Estos se ubican a una distancia de alrededor de $10 \mathrm{~m}$ de las estructuras E5 y E6, por lo que fueron denominados E5 bis y E6 bis, respectivamente.

Durante el proceso de excavación se ha revelado que la construcción de los recintos comprende un muro de doble hilada relleno en su interior con rocas de menor tamaño. Es probable que estos muros se hayan extendido en altura mediante el uso de la técnica de construcción en adobe, hasta alcanzar las dimensiones deseadas. También es factible pensar que estas estructuras pudieron haber funcionado como casas/pozos.

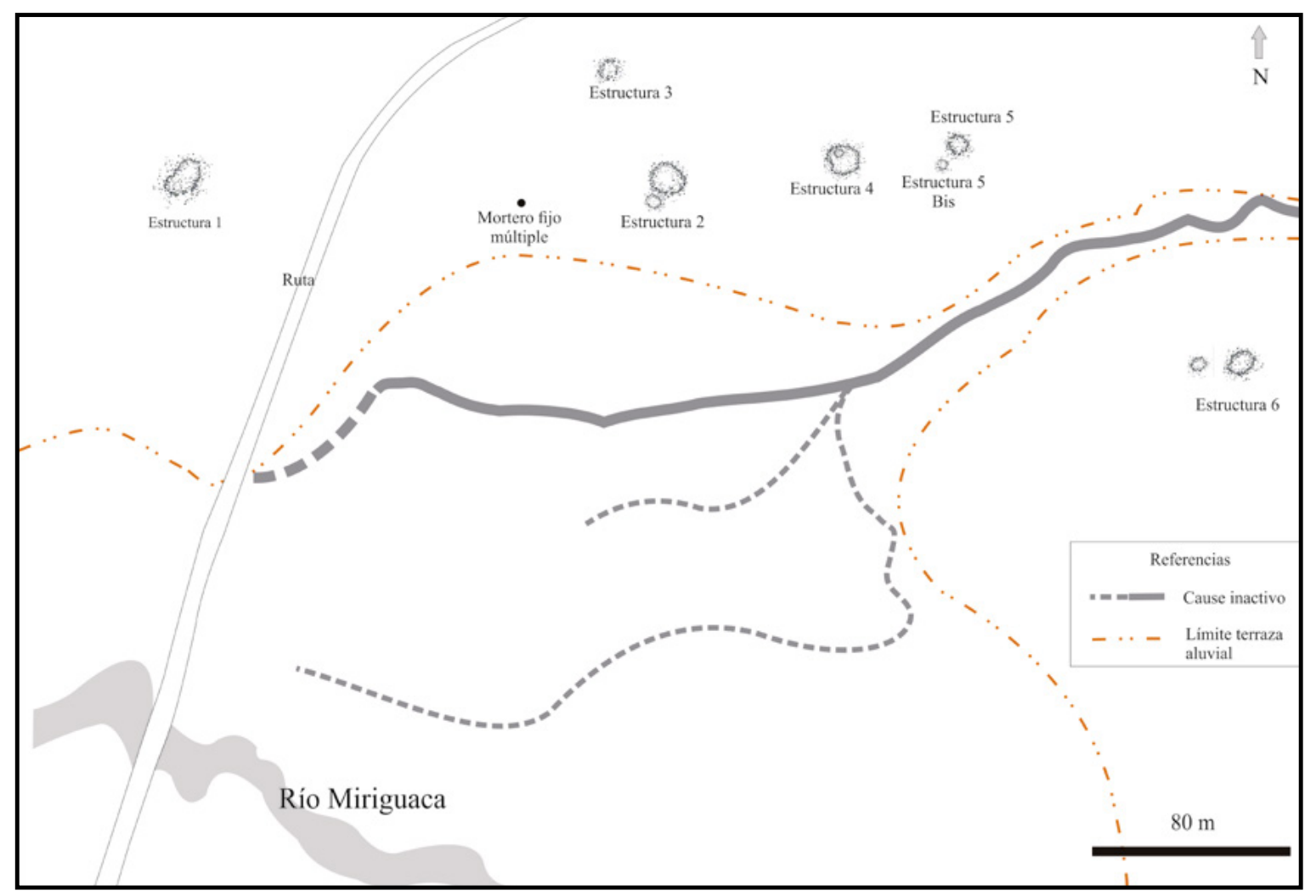

Figura 2. Plano de Las Escondidas. 
Las excavaciones estratigráficas se concentraron fundamentalmente en la E4 que, al momento, registra $45 \mathrm{~m}^{2}$ excavados, cubriendo porciones del interior y del exterior de la misma. Por su parte, las tareas de excavación realizadas en el E5 bis han permitido recuperar importante información, registrando una superficie trabajada de $14 \mathrm{~m}^{2}$.

A partir de las tareas de campo realizadas desde el año 2007 se ha podido ubicar la ocupación de este sitio durante el Formativo temprano, representando uno de los pocos sitios asignados a este momento en la región. Actualmente, se cuenta con cinco fechados radiocarbónicos, que emplazan la ocupación entre los 2.000 y 1.700 años AP aproximadamente (Tabla 1).

Las tareas de excavación también han permitido inferir la utilización de la E4 y la E5 bis como espacios donde se realizaban actividades diferenciadas. Por un lado, la E4 presenta características muy particulares, como la presencia de sedimentos sometidos a altas temperaturas, el hallazgo de importantes cantidades de material vitrificado - del cual aún no se ha establecido un origen certero-, escasa presencia de material cerámico y óseo, variada cantidad de material lítico, en especial la identificación de algunos artefactos alterados por calor (Sentinelli, com. pers.). Todo esto lleva a plantear la posibilidad de que en esta estructura se hayan desarrollado ciertas actividades específicas no ligadas a aquellas de subsistencia o cotidianas, las cuales aún no han sido aclaradas completamente.

Mientras tanto, para el caso de la E5 bis, los contextos conducen a postular que se trataría de un espacio destinado a uso doméstico debido principalmente a hallazgos de fragmentos de vasijas tiznadas, huesos de camélidos asociados a recipientes cerámicos o instrumentos de molienda, entre otros elementos.

Tabla 1. Fechados radiocarbónicos del sitio y su correspondiente calibración.

Esta fue realizada con $2 \sigma$ con el software Oxcal v. 4.1 utilizando la curva ShCal13 (Hogg et al., 2013).

\begin{tabular}{|c|c|c|c|c|c|c|}
\hline $\begin{array}{l}\text { Código de } \\
\text { muestra }\end{array}$ & ${ }^{14} \mathrm{C}$ ańos $\mathrm{AP}$ & $\begin{array}{c}\text { Ańos calibrados } \\
\text { AP ( } 95 \% \\
\text { probabilidad) }\end{array}$ & Años Cal. AP & $\delta^{13} \mathrm{C}$ & $\begin{array}{c}\text { Material- } \\
\text { Procedencia }\end{array}$ & $\mathbf{N}^{\circ}$ laboratorio \\
\hline ESCO-13 & $1737 \pm 50$ & $1726-1484$ & 1612 & $-25.5 \%$ & $\begin{array}{c}\text { Carbón -E4 } \\
\text { Interior } \\
\text { Nivel 2-2 } \\
\text { extracción } \\
\text { Cuadrícula O13 }\end{array}$ & AA82549 \\
\hline ESCO-180 & $1710 \pm 30$ & $1700-1515$ & 1579 & - & $\begin{array}{l}\text { Óseo- E5bis } \\
\text { Interior } \\
\text { Microsector } \\
\text { D- Nivel } 5\end{array}$ & $16 \mathrm{~B} / 0952$ \\
\hline ESCO-158 & $1976 \pm 41$ & 2000-1749 & 1885 & $-18.6 \%$ & $\begin{array}{c}\text { Óseo- E4 } \\
\text { Exterior } \\
\text { Nivel } 2-2^{\circ} \\
\text { extracción } \\
\text { Cuadrícula O19 }\end{array}$ & AA86671 \\
\hline ESCO-116 & $2021 \pm 48$ & $2051-1826$ & 1936 & $-17.5 \%$ & $\begin{array}{c}\text { Óseo- E4 } \\
\text { Interior } \\
\text { Nivel } 2-2^{\circ} \\
\text { extracción } \\
\text { Cuadrícula O17 }\end{array}$ & AA86670 \\
\hline ESCO-44 & $2030 \pm 40$ & $2041-1836$ & 1948 & - & $\begin{array}{c}\text { Óseo - Interior } \\
\text { E4 } \\
\text { Nivel 3-2 } \\
\text { extracción } \\
\text { Cuadrícula Q11 }\end{array}$ & $17 \mathrm{~B} / 0637$ \\
\hline
\end{tabular}


Esta primera aproximación a las funcionalidades de los distintos espacios de este sitio podría ser indicio de la complejidad de esta ocupación.

Ahora bien, ¿̨cómo el material cerámico puede aportar a esclarecer el contexto y las características de esta ocupación?

\section{La cerámica como nodo de la red}

A lo largo de este trabajo los objetos cerámicos son concebidos como aquello que reúne, recolecta y perdura. En este sentido, relacionan en sí mismos cualidades en el tiempo y en el espacio, de modo tal que pueden considerarse como los nodos de una red (Latour, 1996). Esta red está conformada por humanos y cosas, que se constituyen performativamente como un complejo tejido, en donde se entrelazan relaciones entre y sobre las cosas, como una "red de enredos" (sensu Hodder, 2012).

De este modo, si se considera que los objetos se constituyen performativamente con las personas, $y$ que son elaborados en un contexto social determinado, se hace evidente que las cosas poseen una relación dialéctica con la sociedad. Esto es posible desde el momento en que las relaciones sociales se constituyen y desarrollan en un mundo material, a la vez que la cultura material resulta activa en la construcción, reconstrucción y cambio de dichas relaciones sociales.

Entonces, un objeto reúne en sí mismo la interrelación de habilidades, conocimientos, destrezas, valores, metas, necesidades funcionales, actitudes, tradiciones, relaciones de poder, constreńimientos materiales y productos finales, junto con el artificio y las relaciones sociales (Dobres, 1999). De esta forma, se puede ver un objeto como el que ensambla en sí mismo toda una red de enredos, en la que se interrelacionan, entre otros, aspectos materiales, sociales y simbólicos, los cuales adquieren significado en un contexto social particular.

Por lo tanto, las cosas forman parte y son, en sí mismas, un enredo (sensu Hodder, 2012). Así, cuando se entiende una vasija cerámica como un objeto conformado de un solo bloque -como algo acabado en sí mismo-, se pierde de vista la multiplicidad de materiales que en él se ven implicados. En este sentido, el "enredo alfarero" ${ }^{4}$ comienza a hilvanar sus hebras con la obtención de las materias primas, es decir, la localización de arcillas, antiplásticos, agua, pigmentos para la decoración, combustible, etcétera. Luego, durante la preparación del cuerpo de arcilla se debe tener en cuenta que se puede realizar la extracción de materiales no deseados o bien el agregado de antiplásticos de diferentes características, todo dependiendo de la intencionalidad del alfarero. También durante el modelado de la vasija se utilizan diferentes herramientas, reflejándose así cómo son necesarios otros elementos para la elaboración de una vasija. Finalmente, el enredo involucra los tratamientos superficiales que implican baños, engobes, pintura, etcétera, ya sean antes o después de la cocción y, en definitiva, la cocción misma, en donde entra en juego la necesidad de controlar la velocidad de calentamiento, la temperatura máxima y la atmósfera que rodea al objeto, como también el combustible necesario para la cocción (Cremonte, 1983-1985; Rice, 1987; Rye, 1988; Orton, Tyers y Vince, 1997). Desde un punto de vista social y/o simbólico, también a lo largo del enredo alfarero se tejen innumerables redes, entre diferentes personas y objetos, que traspasan espacios y temporalidades, involucrando procesos, elecciones (sensu Lemonnier, 1993) y relaciones contextualizadas dentro de un espacio social e histórico determinado (Bourdieu, 1977, 1997).

Entonces, podría ser posible que, al volver a lo material, fuera factible indagar en los enredos en los que se vieron involucradas las personas en la fabricación, uso y mantenimiento de cada objeto cerámico.

\section{Materiales y métodos}

El material cerámico recuperado hasta el momento en Las Escondidas consiste en 621 fragmentos cerámicos, procedentes tanto de recolección superficial como de las excavaciones de la E4 y E5 bis. El conjunto se presenta bastante fragmentado, y la

4 La idea de un "enredo alfarero" es propia, y se tomó como una aplicación específica de lo desarrollado por Hodder directamente referida a la problemática de la manufactura cerámica. 
posibilidad de remontaje dentro del mismo fue extremadamente baja.

El conjunto bajo estudio está conformado por 190 fragmentos obtenidos de la totalidad de recolección superficial realizada durante los ańos 2012 y 2014; 71 procedentes de la excavación de la E4 y 360 fragmentos de la E5 bis. Como estos números lo reflejan, la mayor cantidad de fragmentos provienen de la E5 bis. Dentro de este conjunto $(\mathrm{n}=621)$ se pudieron identificar diversas partes de vasijas, entre las que se destacan las partes indeterminadas $(50,08 \%)$, luego los fragmentos correspondientes a cuerpos $(33,82 \%)$, seguidos por los bordes $(5,31 \%)$, bordes y cuerpo $(2,25 \%)$ y bordes y cuellos $(2,25 \%)$, entre otros en menor representación.

Partiendo de este panorama, la metodología aplicada fue desarrollada en dos etapas, la primera realizada a nivel macroscópico (ojo desnudo y lupa de bajos aumentos), y la segunda a nivel microscópico (petrografía de pastas).

Cabe aclarar que, aunque la totalidad del conjunto cerámico analizado es de carácter fragmentario, se consideró que tomar los fragmentos como unidad de análisis no era lo adecuado en esta oportunidad. Por lo tanto, se asociaron fragmentos en grupos que podrían responder a una misma pieza.

Esta separación fue realizada sobre la base de la observación macroscópica de variables referidas a diversas elecciones tecnológicas (Lemonnier, 1993), tomadas durante distintas etapas de la manufactura (Cremonte, 1983-1985; Rye, 1988; Sinopoli, 1991; Orton et al., 1997; Zagorodny, 2000).

Para realizar esta separación se observaron diversos atributos que refieren a la manufactura, como aquellos relacionados con el preparado de la arcilla, el levantado de la pieza, los tratamientos y acabados superficiales, la cocción y, finalmente, la existencia de marcas o trazas relacionadas con el uso y el descarte o depositación. Las semejanzas en dichas características permiten suponer que un grupo de fragmentos determinados podrían corresponder a un mismo objeto cerámico (Orton et al., 1997). Estos grupos fueron denominados Familias de Fragmentos.
La observación se realizó sobre cada fragmento individual, lo que no implicó dejar de lado la categoría de Familia de Fragmentos, ya que mediante esta elección metodológica fue posible generar una base de datos más completa y detallada, considerando que un mismo objeto cerámico puede presentar en distintas partes diferentes características tecnológicas.

Una vez obtenido un panorama general del conjunto, que incluyó formas, tamaños, tratamientos de superficies, etcétera, se procedió a realizar la segunda etapa del análisis, que consistió en análisis petrográficos de pastas a partir de cortes delgados, para lo cual se seleccionó una determinada cantidad de fragmentos $(n=43)$ considerada representativa de la variabilidad detectada en las familias antes establecidas.

La descripción de las pastas cerámicas al microscopio se realizó mediante el análisis de distribución modal de tres elementos: matriz, inclusiones y cavidades o poros. En cada corte se realizó un conteo de puntos, mínimo 300 , recorriendo la extensión horizontalmente y cubriendo toda la superficie, contando a intervalos constantes $(1 \mathrm{~mm})$ los elementos sobre los cuales se posó la cruz del retículo (Pereyra Domingorena, 2010). Durante este conteo también se tuvieron en cuenta los fondos de pasta o matrices y la determinación mineralógica de las inclusiones mayores a $10 \mu \mathrm{m}$. Al mismo tiempo, se registraron las formas, tamaños, angulosidad y esfericidad de las inclusiones no plásticas, y de las cavidades (Cremonte, 1996). Para este análisis se utilizó un microscopio de petrográfico de polarización marca Bio-Traza modelo XP-148PLT.

Una vez obtenidos los resultados del conteo de puntos se realizó el tratamiento estadístico de la información. Para ello, los porcentajes estimados de matriz, cavidades y de diversas inclusiones no plásticas fueron procesados con el programa estadístico PAST V.3 para así aplicar un análisis de componentes principales y, luego, proceder al análisis estadístico de conglomerados jerárquicos, que posibilitó definir distintos tipos de pastas (Hammer, Harper y Ryan, 2001). La aplicación del análisis de conglomerado jerárquico permitió diferenciar las relaciones que existen entre las muestras analizadas, en función de sus similitudes y disimilitudes (Cremonte, 1996). 


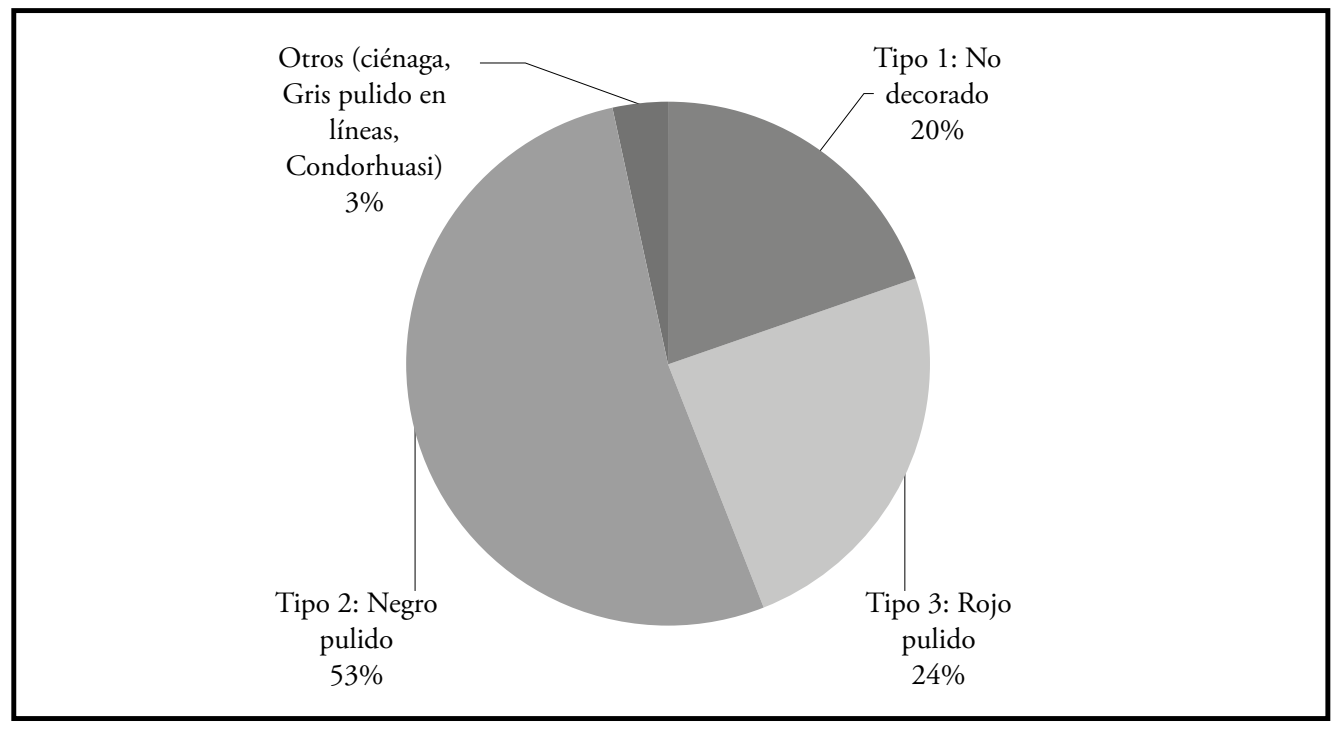

Figura 3. Porcentajes de cada tipo establecido con base en sus acabados superficiales.

Cabe destacar que este abordaje permite la segregación de tipos petrográficos o tipos de pastas, los cuales son definidos sobre la base de una sección delgada o un grupo de ellas que tienen una combinación específica de inclusiones, matriz arcillosa y poros, y que presenta alguna diferencia significativa respecto de otras muestras dentro del grupo estudiado. De esta forma, tipos petrográficos de pastas están definidos por sus ingredientes constitutivos y por las formas en las cuales estas fueron preparadas y combinadas (Quinn, 2013).

En definitiva, la caracterización petrográfica de los tipos de pasta brinda información sobre las elecciones tecnológicas tomadas por los alfareros durante algunas etapas de las cadenas operativas, y también permite plantear hipótesis acerca de la selección y el tratamiento de las materias primas, el carácter local o no local de las mismas y la existencia o no de elecciones tecnológicas compartidas (Cremonte, 1996).

\section{Resultados}

El conjunto cerámico analizada presentaba, en líneas generales, características estilísticas muy específicas y particulares que permitieron establecer, basados en la observación de atributos referentes a los acabados superficiales, la distinción de cuatro grandes tipos de cerámica.
Al primer grupo, más numeroso, se denominó Tipo 1 No decorado y se caracteriza por presentar fragmentos sin decoración y con acabados poco cuidadosos ( $\mathrm{n}=403)$. El segundo grupo (Tipo $2 \mathrm{Negro} \mathrm{Pu}-$ lido) está conformado por una cerámica negra, que presenta la aplicación de un engobe grueso y una superficie cuidadosamente pulida $(\mathrm{n}=155)$. Luego, se separó también un conjunto de fragmentos de color rojo (Tipo 3 Rojo Pulido), algunos con manchas oscuras como efectos de una cocción irregular, con acabados de superficie muy similares a los del Tipo $2(n=58)$. Finalmente, hay un pequeño grupo que se conformó con escasos ejemplares de fragmentos posiblemente asignables a Saujil pulido en líneas (Sempé, 1977), Ciénaga y Condorhuasi Río Diablo (González, 1956) ${ }^{5}$ considerando su decoración característica $(\mathrm{n}=5)$ (Figura 3$)$.

Esta primera separación sirvió para, posteriormente, realizar un agrupamiento más certero entre los

5 El estilo cerámico Condorhuasi Río Diablo fue definido partiendo de las evidencias recolectadas para el valle de Hualfín (Provincia de Catamarca, Argentina) y fue ubicado temporalmente entre el 200 AC y el 200 DC. Mientras tanto, la cerámica conocida como Saujil fue definida para el valle de Abaucán (Provincia de Catamarca, Argentina) y vinculada con los conjuntos más tempranos de la tradición alfarera del Noroeste argentino (como San Francisco, Las Cuevas, Tafí, etc.). Tradicionalmente se la ubica cronológicamente hacia los comienzos de la era. 


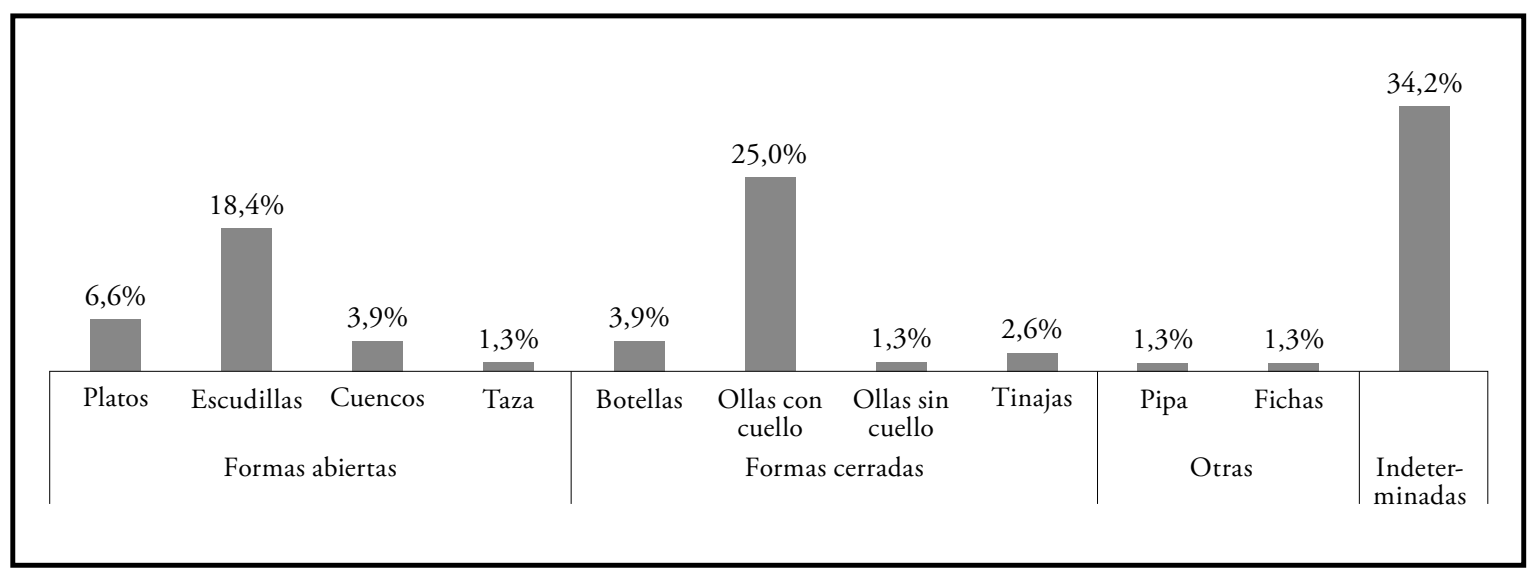

Figura 4. Formas identificadas en el conjunto cerámico de Las Escondidas.

fragmentos que podrían pertenecer a una misma vasija, tal como fue desarrollado anteriormente. Así, se planteó la existencia de 73 Familias de Fragmentos que refieren, en última instancia, a la existencia de al menos 73 vasijas en las estructuras E4 y E5 bis. De este total, 24 familias corresponden al Tipo 1, 31 al Tipo 2, 16 al Tipo 3 y 2 a "Otros". Estos grupos luego fueron clasificados según sus formas, entre abiertas y cerradas, tal como proponen Balfet, Bertehelot y Monzón (1991), partiendo de los fragmentos diagnósticos, tales como bordes, bases y cuerpos.

Dentro de estos 74 grupos, se definieron 22 formas abiertas, 25 formas cerradas y 26 indeterminadas. A estas se debe sumar un grupo de fichas $(n=3)$ y uno de fragmentos de pipas $(n=2)$ (Figura 4). Por su parte, las formas abiertas pudieron desdoblarse en platos $(n=5)$, escudillas $(n=14)$, cuencos $(n=3)$ y taza $(\mathrm{n}=1)$. Mientras tanto, en las formas cerradas se distinguieron ollas con cuello $(\mathrm{n}=19)$, olla sin cuello $(\mathrm{n}=1)$, tinajas $(\mathrm{n}=2)$ y botellas $(\mathrm{n}=3)$ (ver Figura 4$)$.

Ahora bien, estas vasijas presentan variabilidad en sus características. En las formas abiertas se registró un amplio rango de tamaños que pueden ir desde $18 \mathrm{~cm}$ a $30 \mathrm{~cm}$ de diámetro en las bocas (Figura 5). Por su parte, los espesores promedio de las paredes registraron desde $4,0 \mathrm{~mm}$ a $8,6 \mathrm{~mm}$, destacándose los más gruesos en las escudillas (Escudilla LE-19) y en los platos (Plato LE-71), mientras que los espesores más reducidos también se encuentran en las escudillas (Escudilla LE-7) y los cuencos (Cuenco LE-18) (Figura 6).
En términos generales, y en los pocos casos en que se pudo apreciar alguna marca referida a la técnica de levantado de las piezas, estas siempre se relacionan con la presencia de rollos o rodetes.

Los acabados superficiales en las formas abiertas son muy homogéneos, predominando el aplique de engobes en ambas superficies, para ser posteriormente pulidos. Luego, las piezas fueron cocidas, principalmente en atmósferas reductoras (Shepard, 1954), ${ }^{6}$ lo cual les dio un aspecto característico con superficies negras, como se describió para el conjunto denominado Tipo 1, aunque también se registraron algunos casos de cocción oxidante, que dio como resultado el Tipo mencionado en un principio como "Rojo Pulido". Asimismo, se detectó todo un abanico de variaciones en la cocción que fueron clasificadas como oxidante incompleta o reductora incompleta, que se traducen en piezas con manchas o variaciones de color.

Dentro de este conjunto prácticamente no hay evidencias de uso y, además, se observaron escasas marcas de alteraciones posdepositacionales como descascarados o erodados en las superficies. Es interesante destacar que en dos casos de escudillas se observaron orificios correspondientes a la reparación de las piezas, lo cual podría indicar una intencionalidad de

6 Al hacer referencia a una atmósfera reductora se debe tener en cuenta que es muy difícil que se haya logrado una cocción cien por ciento libre de oxígeno, pero tal vez se haya podido realizar algún proceso que resultó en el oscurecimiento de las superficies y del núcleo, como un ahumado al final de la cocción. 


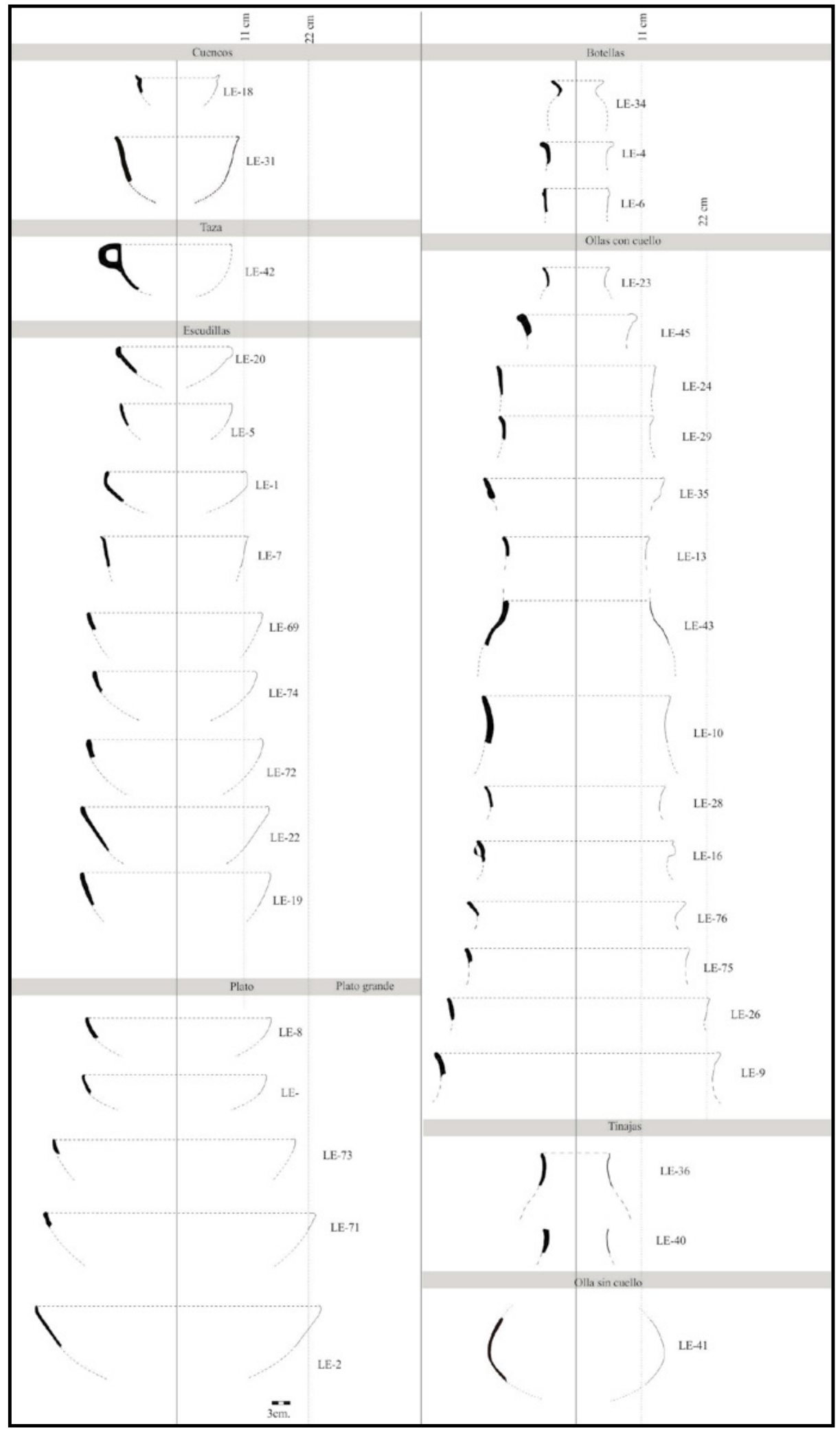

Figura 5. Formas identificadas en Las Escondidas. 


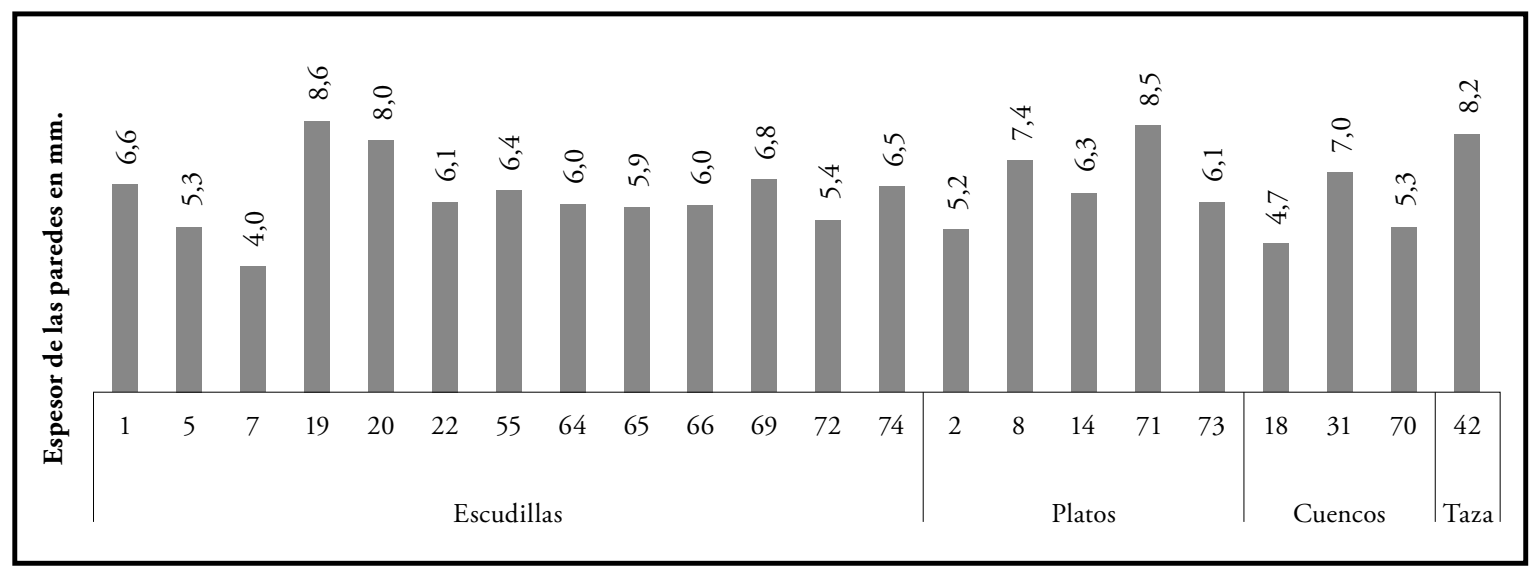

Figura 6. Espesores promedio de las paredes en formas abiertas.

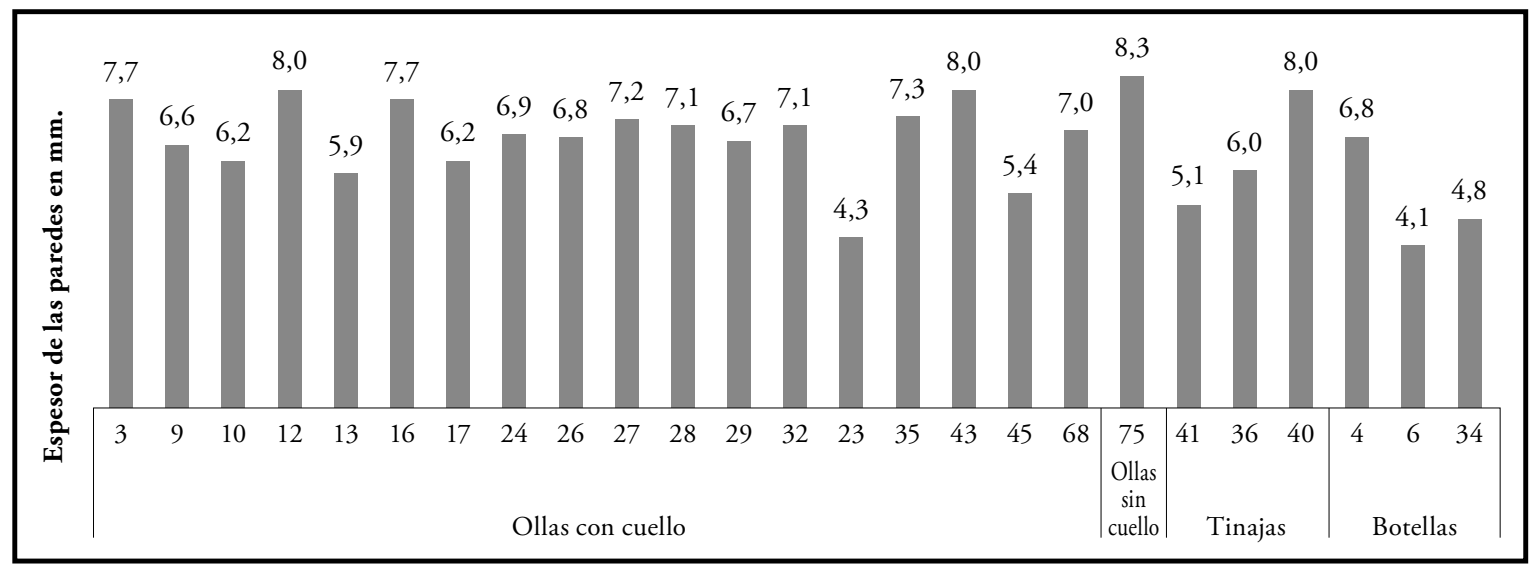

Figura 7. Espesores promedio de las paredes en las formas cerradas.

conservar dichas vasijas en la esfera del uso incluso después de haberse roto.

Para el otro gran conjunto -las formas cerradas-, como ya se mencionara, se definieron cuatro subconjuntos (ollas con cuello, olla sin cuello, tinajas y botellas) (ver Figura 5). En general, estas formas se presentan como un conjunto bastante heterogéneo, que muestra aberturas de diversos tamaños en las bocas. Sin embargo, predominan piezas de tamaños grandes y bordes evertidos (olla sin cuello LE-75, olla con cuello LE-26 y olla con cuello LE-9), las cuales podrían haber sido fabricadas para algún fin específico o bien siguiendo cierto patrón.

Por su parte, las dos piezas consideradas tinajas (LE-41, LE-36 y LE-40) son muy parecidas entre sí, aunque el tratamiento de las superficies difieren bastante. Estas dos vasijas podrían haber sido confeccionadas para el almacenaje de líquidos, ya que sus formas beneficiarían su conservación, preservando de la evaporación y siendo adecuados para verterlos. Lo mismo sucede con las botellas (LE-4, LE-6, y LE-34), que serían muy apropiadas para servir y transportar líquidos, aunque su capacidad sería mucho menor que la de las tinajas.

Para el conjunto de formas cerradas también se promedió el espesor de las paredes para cada vasija hipotética. En general, los espesores pueden variar entre los 4,1 $\mathrm{mm}$ hasta los $8,3 \mathrm{~mm}$ (Figura 7).

En cuanto a los tratamientos que recibieron las superficies, en las botellas y ollas con cuello predominan los engobes en ambas superficies. Para las tinajas se observaron casos con engobes solo en la superficie 
externa o directamente sin tratamientos. Por otro lado, en la olla sin cuello no se observó la aplicación de ningún elemento en las superficies.

Luego de los engobes, la mayoría de las piezas fueron pulidas en ambas superficies, especialmente las ollas con cuello y las botellas, aunque también se observaron alisados, pulido en solo una superficie y alisado, con rastros del instrumento utilizado para esta tarea. Es posible que estas piezas fueran pulidas únicamente en el sector visible y accesible del interior, como son los bordes.

Debido posiblemente tanto a las características de los engobes como a las condiciones de la cocción, entre las formas cerradas predominan aquellas asociadas al Tipo 2 (Negro Pulido) $(\mathrm{n}=12)$, seguidas por el Tipo $1(\mathrm{n}=7)$ y finalmente aquellas reconocidas como pertenecientes al Tipo 3 (Rojo Pulido) $(n=6)$.

Respecto a las evidencias de uso, es muy baja la presencia de indicadores. En las ollas con cuello, la mayoría de las piezas no presenta evidencias $(n=16)$, así como tampoco se observan en las tinajas $(n=2)$ y en las botellas $(\mathrm{n}=3)$. La única pieza que muestra claros rastros de uso es la olla sin cuello que, específicamente, denota exposición al fuego y superficies tiznadas. Esto podría llevar a proponer el desarrollo de actividades domésticas, como la cocción de alimentos en vasijas cerámicas, en la E5 bis. Esto se respalda, además, por la identificación de fogones y restos óseos animales en esta estructura, asociados a las vasijas.

Finalmente, en relación a las evidencias de alteraciones posdepositacionales, se destacan las ollas con cuello, en las que se observaron, por lo menos en 14 casos, descascarados y erodados. Los descascarados tienen que ver principalmente con el desprendimiento del engobe, lo que podría deberse a las condiciones de depositación de los fragmentos, muchos de los cuales provienen de superficie. Aunque esto también pudo haberse producido durante su uso.

El grupo de Familias de Fragmentos catalogado como Formas indeterminadas es muy semejante a los descritos anteriormente, aunque en este caso predominan aquellas familias asociadas al Tipo 1 (No decorado) $(\mathrm{n}=17)$, seguido por cuatro familias asociadas al Tipo 2 y luego tres familias correspon- dientes al Tipo 3. Dentro de este conjunto también se agruparon dos Familias de Fragmentos asociadas a los tipos estilísticos conocidos como Condorhuasi y Saujil pulido en líneas. ${ }^{8}$

Una vez establecido este panorama, se procedió a realizar los estudios petrográficos correspondientes.

Para esta etapa del análisis se seleccionaron 43 muestras. Cada una de ellas representa una vasija determinada, correspondiente a una de las Familias de Fragmentos agrupadas anteriormente. Las muestras seleccionadas corresponden a 6 escudillas, 3 platos, 2 cuencos, 1 taza, 16 ollas con cuello, 1 olla sin cuello, 2 tinajas, 3 botellas y 9 fragmentos de formas indeterminadas (Tabla 2).

Tabla 2. Formas y tipo cerámico correspondientes a cada muestra.

\begin{tabular}{|c|c|c|}
\hline Forma & Muestra & $\begin{array}{l}\text { Tipo por acabado } \\
\text { superficial }\end{array}$ \\
\hline Escudillas & $\begin{array}{l}\text { LE-1 } \\
\text { LE-5 } \\
\text { LE-7 } \\
\text { LE-19 } \\
\text { LE-20 } \\
\text { LE-22 }\end{array}$ & $\begin{array}{l}\text { Tipo } 2 \text { Negro Pulido } \\
\text { Tipo } 2 \text { Negro Pulido } \\
\text { Tipo } 3 \text { Rojo Pulido } \\
\text { Tipo } 3 \text { Rojo Pulido } \\
\text { Tipo } 3 \text { Rojo Pulido } \\
\text { Tipo } 3 \text { Rojo Pulido }\end{array}$ \\
\hline Platos & $\begin{array}{l}\text { LE-2 } \\
\text { LE-8 } \\
\text { LE-14 }\end{array}$ & $\begin{array}{l}\text { Tipo } 2 \text { Negro Pulido } \\
\text { Tipo } 3 \text { Rojo Pulido } \\
\text { Tipo } 2 \text { Negro Pulido }\end{array}$ \\
\hline Cuencos & $\begin{array}{l}\text { LE-18 } \\
\text { LE-31 }\end{array}$ & $\begin{array}{l}\text { Tipo } 2 \text { Negro Pulido } \\
\text { Tipo } 2 \text { Negro Pulido }\end{array}$ \\
\hline Taza & LE-42 & Tipo 2 Negro Pulido \\
\hline Olla con cuello & $\begin{array}{l}\text { LE-3 } \\
\text { LE-9 } \\
\text { LE-10 } \\
\text { LE-12 } \\
\text { LE-13 } \\
\text { LE-16 } \\
\text { LE-17 } \\
\text { LE-23 } \\
\text { LE-24 } \\
\text { LE-26 } \\
\text { LE-27 } \\
\text { LE-28 } \\
\text { LE-29 } \\
\text { LE-32 } \\
\text { LE-35 } \\
\text { LE-43 }\end{array}$ & $\begin{array}{l}\text { Tipo } 2 \text { Negro Pulido } \\
\text { Tipo } 1 \text { No decorado } \\
\text { Tipo } 1 \text { No decorado } \\
\text { Tipo } 1 \text { No decorado } \\
\text { Tipo } 2 \text { Negro Pulido } \\
\text { Tipo } 2 \text { Negro Pulido } \\
\text { Tipo } 2 \text { Negro Pulido } \\
\text { Tipo } 3 \text { Rojo Pulido } \\
\text { Tipo } 3 \text { Rojo Pulido } \\
\text { Tipo } 3 \text { Rojo Pulido } \\
\text { Tipo } 1 \text { No decorado } \\
\text { Tipo } 2 \text { Negro Pulido } \\
\text { Tipo } 2 \text { Negro Pulido } \\
\text { Tipo } 2 \text { Negro Pulido } \\
\text { Tipo } 3 \text { Rojo Pulido } \\
\text { Tipo } 2 \text { Negro Pulido }\end{array}$ \\
\hline
\end{tabular}




\begin{tabular}{|c|c|c|}
\hline Olla sin cuello & LE-41 & Tipo 1 No decorado \\
\hline Tinajas & $\begin{array}{l}\text { LE-36 } \\
\text { LE-40 }\end{array}$ & $\begin{array}{l}\text { Tipo } 1 \text { No decorado } \\
\text { Tipo } 3 \text { Rojo Pulido }\end{array}$ \\
\hline Botellas & $\begin{array}{l}\text { LE-4 } \\
\text { LE-6 } \\
\text { LE-34 }\end{array}$ & $\begin{array}{l}\text { Tipo } 3 \text { Rojo Pulido } \\
\text { Tipo } 2 \text { Negro Pulido } \\
\text { Tipo } 3 \text { Rojo Pulido }\end{array}$ \\
\hline Indeterminada & $\begin{array}{l}\text { LE-11 } \\
\text { LE-15 } \\
\text { LE-21 } \\
\text { LE-25 } \\
\text { LE-30 } \\
\text { LE-33 } \\
\text { LE-37 } \\
\text { LE-38 } \\
\text { LE-39 }\end{array}$ & $\begin{array}{l}\text { Tipo } 1 \text { No decorado } \\
\text { Tipo } 2 \text { Negro Pulido } \\
\text { Otros } \\
\text { Tipo } 3 \text { Rojo Pulido } \\
\text { Tipo } 1 \text { No decorado } \\
\text { Tipo } 1 \text { No decorado } \\
\text { Otros } \\
\text { Tipo } 3 \text { Rojo Pulido } \\
\text { Otros }\end{array}$ \\
\hline
\end{tabular}

Siguiendo lo ya expuesto en el apartado Metodología, a continuación se presentan los resultados correspondientes a este análisis, en los que se registraron las variables matriz, cavidades e inclusiones no plásticas. Específicamente, en este caso se registraron 27 tipos diferentes de inclusiones no plásticas, entre las que se encuentran: cuarzo, cuarzo con extinción ondulante, plagioclasa, microclino, muscovita, biotita, feldespatos alterados, plagioclasa alterada a sericita, pertita, minerales opacos, olivino, anfíbol, rocas graníticas, sericita, rocas volcánicas no identificadas, vulcanita ${ }^{7}$ (Aschero, Escola, Hocsman y Martínez, 2002-2004), ignimbrita, litoclastos volcánicos alterados generalmente a sericita, estructuras de desvitrificación con hábito esferulítico, rocas carbonáticas, rocas metamórficas, pizarras, cuarcita, litoclastos alterados sin posibilidad de identificación, areniscas y tiesto molido. Cabe mencionar que no todas las variedades de inclusiones fueron observadas en todas las muestras (Tabla 3).

Los resultados obtenidos fueron trabajados estadísticamente. El análisis de componentes principales, aplicando la matriz de varianza-covarianza, arrojó como resultado que los componentes que reúnen el

7 En toda oportunidad en que en el texto se mencione el término Vulcanita, este hace referencia a litoclastos volcánicos con textura traquitica (microlitos de plagioclasa dispuestos al azar rodeando a otros máfitos). Podría tratarse de andesitas, pero no pudieron ser identificadas específicamente. Este término se emplea en consonancia a lo propuesto para la determinación de materias primas líticas de la región. mayor porcentaje de varianza son los componentes 1 y 2 . El componente 1 comprende el $55 \%$ de la varianza, mientras que el componente 2 reúne un $21 \%$, representando entonces, a partir de estos dos componentes, el $76 \%$ de la varianza total de todo el conjunto.

El componente principal 1 representa una elevada correlación positiva con las inclusiones de cuarzo, mientras que muestra una correlación negativa fuerte con los porcentajes de matriz. Por su parte, el componente principal 2 presenta una alta correlación con las inclusiones de cuarzo, mientras que presenta una correlación negativa fuerte con las inclusiones de plagioclasas sericitizadas, asociadas a la alteración de minerales.

Posteriormente, se efectuó un análisis de conglomerados jerárquicos, aplicando el método de pares agrupados, obteniendo un coeficiente cofenético de 0,788 y resultando en un conglomerado estadístico que arrojó ocho conjuntos diferenciados que, en adelante, serán referidos como Tipos petrográficos (Figura 8).

Partiendo de estos análisis, se pudieron segregar las pastas de acuerdo a los porcentajes de matriz e inclusiones observadas. Se identificaron tres tipos generales de pastas: a) pastas gruesas, con porcentajes de matriz inferiores al $35 \%$ e inclusiones no plásticas superiores al 55\%; b) pastas intermedias, con porcentajes de matriz que van desde $36 \%$ al $60 \%$ e inclusiones no plásticas entre $35 \%$ y $60 \%$ y finalmente; c) pastas finas, con porcentajes de matriz superiores al 54\% e inclusiones no plásticas entre $25 \%$ y $42 \%$ (Figura 9).

Cada uno de los grupos de pasta definidos está conformado por distintos tipos petrográficos. El grupo más numeroso es el de las pastas intermedias, que comprende tres tipos petrográficos con 23 muestras, seguido por el grupo de pastas gruesas, compuesto por tres tipos petrográficos, integrando 15 muestras. Finalmente, se ubica el grupo de pastas finas, que agrupa dos tipos petrográficos con tres muestras. 
Tabla 3. Composición de cada muestra. Referencias: Mat. (matriz), Cav. (cavidades), Cz. Ond. (cuarzo con extinción ondulante), Plag. (plagioclasa), Mic. (microclino), Musc. (muscovita), Biot. (biotita), Feld. (feldespato), Feld. Alt. (feldespato alterado), Plag. Ser. (plagioclasa sericitizada), Pert. (pertita), M. Op. (minerales opacos), Oliv. (olivino), Anf. (anfíbol), R. Gran. (rocas graníticas), Ser. (sericita), R. Volc. (rocas volcánicas no identificadas), Vc. (vulcanita), Ign. (ignimbrita), L.V.A. (litoclastos volcánicos alterados), Est. Des. (estructura de desvitrificación), R. Car. (rocas carbonáicas), R. Met. (rocas metamórficas), Piz/Fil. (pizarra o filita), Cu. (cuarcita), Lit. Alt. (litoclastos alterados no identificables), Arenisc. (arenisca) y Ti Mol. (tiesto molido).

\begin{tabular}{|c|c|c|c|c|c|c|c|c|c|c|c|c|c|c|c|c|c|c|c|c|c|c|c|c|c|c|c|c|c|c|c|c|c|c|c|c|c|c|c|c|c|}
\hline$=\dot{0}$ & $\stackrel{0}{0}$ & I & & & & \begin{tabular}{l}
$\stackrel{2}{2}$ \\
\multirow{2}{0}{}
\end{tabular} & $\begin{array}{l}\infty \\
0 \\
0 \\
0\end{array}$ & & & & & & & $\begin{array}{l}\overrightarrow{3} \\
\overrightarrow{0}\end{array}$ & 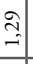 & בี & \begin{tabular}{c|}
$\infty$ \\
$\ldots$ \\
0 \\
0
\end{tabular} & & $\begin{array}{c}\hat{2} \\
0\end{array}$ & & & $\begin{array}{l}0 \\
\vdots \\
0 \\
0\end{array}$ & $\begin{array}{l:l}0 & 1 \\
0 & 1 \\
0 & \end{array}$ & $=$ & ?. & & & 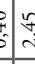 & & & 吾 & & & & & 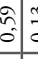 & 0 & & $\begin{array}{l}\beth \\
0\end{array}$ & & $\begin{array}{l}\bumpeq \\
= \\
=\end{array}$ \\
\hline 它它 & & & & & & & & & & & & & & & & & & & & & & & & & & & & $\frac{7}{0}$ & & & & & & & & & & & & & \\
\hline ث் & & & & & & & & & & & & & & & & & & & & & & & & & & & & & & & & & & $\begin{array}{l}\text { t. } \\
\text { s. }\end{array}$ & & & & & & & \\
\hline ن் & & $\frac{1}{0}$ & & & & & & & & & & & & & & & & & & & & & & & & & & 5 & & & $\underset{\sim}{-1}$ & & & & $\begin{array}{l}0 \\
: \\
-1\end{array}$ & $\begin{array}{l}n \\
0 \\
0\end{array}$ & & $\begin{array}{l}\tilde{y} \\
\tilde{c} \\
0\end{array}$ & & & $\begin{array}{l}7 \\
0\end{array}$ \\
\hline $\bar{N} \bar{X}$ & & & & & $\approx$ & & $\begin{array}{l}n \\
0 \\
0\end{array}$ & & & & & & & & & & & & & & & & & & & & & & & & & & & & & & & & & & \\
\hline$\therefore \dot{\sim}$ & & & & & & & & & & & & & & & & है & & & & & & & & & & & & z้ & & & & & & & $\begin{array}{c}2 \\
n \\
n\end{array} \mid$ & & & & & & \\
\hline$\dot{\sim}$ & & f & & & & & & & & & & & & & & & & & & & & & & & & & & & & & & & $\begin{array}{l}\text { f } \\
0 \\
0\end{array}$ & 足 & & $\begin{array}{l}n \\
0 \\
0\end{array}$ & & $\begin{array}{l}\infty \\
3 \\
0 \\
0 \\
0\end{array}$ & & & \\
\hline 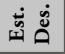 & & & & & & & & & & & $\stackrel{\infty}{\sim}$ & & & & & & & & & & & & & & & & & & & & & & & & & & & & & & \\
\hline 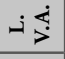 & & & & & & & & & & & & & & & & & & & & & & & & & & & & & & & & & & \begin{tabular}{|l|}
$\infty$ \\
0 \\
-2 \\
\end{tabular} & & & & & & & \\
\hline do. & & & & & & & & & & & & & & & & & & & & & & & & & & & & & & & & & & & & & & & & $\begin{array}{l}0 \\
\stackrel{1}{0} \\
0\end{array}$ & \\
\hline$\dot{u}_{-}$ & & & & & & & & & & & & & & & & & & & & & & & & & & & & & & & & & & & & & & & & $\begin{array}{l}\approx \\
0\end{array}$ & \\
\hline$\therefore \overline{>}$ & & & & & & & $\begin{array}{l}n \\
0\end{array}$ & & $\begin{array}{l}\text { त̂ } \\
0 \\
\end{array}$ & $\begin{array}{l}\text { I } \\
\text { f } \\
\end{array}$ & & & & & & & & & & & $=$ & & & & & d & 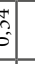 & & & & & & 0 & & \begin{tabular}{|l|l} 
& \\
0 & \\
0
\end{tabular} & ชิ & & & & $\begin{array}{l}\hat{2} \\
\hat{0}\end{array}$ & \\
\hline ڤั & 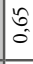 & $\begin{array}{l}\tilde{n} \\
\sim \\
i\end{array}$ & & 今. & & & $\begin{array}{l}n \\
0 \\
0\end{array}$ & & & & & & & $\overrightarrow{\tilde{n}}$ & $\begin{array}{l}\circ \\
\infty \\
0 \\
\end{array}$ & & & $\begin{array}{l}\infty \\
0 \\
0\end{array}$ & $\begin{array}{l}m \\
\text { ?. } \\
0\end{array}$ & & & $\stackrel{\mathrm{m}}{\Rightarrow}$ & $\overrightarrow{\hat{c}^{2}}$ & & & & 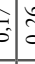 & & & & & & & $\begin{array}{l}\text { In } \\
0 \\
0\end{array}$ & \begin{tabular}{|l|l} 
\\
0 \\
0
\end{tabular} & $\begin{array}{l}8 \\
\text { i }\end{array}$ & & $\begin{array}{l}n \\
\hat{0} \\
0\end{array}$ & & & \\
\hline 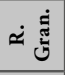 & 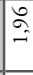 & $\begin{array}{l}\infty \\
0 \\
0\end{array}$ & & is & $\begin{array}{l}\infty \\
\infty \\
n^{2}\end{array}$ & - & 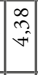 & 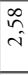 & 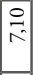 & $\begin{array}{l}\tilde{n} \\
\tilde{a} \\
=\end{array}$ & 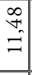 & के & \begin{tabular}{|l|}
$\overrightarrow{0}$ \\
$\vec{i}$
\end{tabular} & $\begin{array}{l}3 \\
\text { in } \\
\text { in }\end{array}$ & $\hat{n}$ & ज़ & 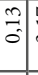 & $\begin{array}{c}\Rightarrow \\
m\end{array}$ & बे & స్. & त्ञ & \begin{tabular}{l|l}
0 \\
0 \\
0
\end{tabular} & $\stackrel{2}{\approx}$ & 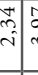 & की & $=0$ & $=$ & $=$ & $\begin{array}{c}b \\
b \\
c\end{array}$ & $\begin{array}{l}0 \\
b \\
b\end{array}$ & $\begin{array}{l}\hat{n} \\
m\end{array}$ & $\begin{array}{l}n \\
\sim \\
\sim\end{array}$ & - & $\mid \begin{array}{l}0 \\
0 \\
i \\
\end{array}$ & $\begin{array}{l}n \\
\hat{o} \\
\hat{n}\end{array}$ & 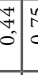 & 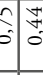 & $\mid \begin{array}{l}\infty \\
\infty \\
0 \\
0\end{array}$ & \begin{tabular}{l|}
0 \\
$\infty$ \\
0 \\
0
\end{tabular} & $\begin{array}{c}\tilde{2} \\
\vdots \\
0\end{array}$ & O3 \\
\hline$\dot{3}$ & & & & & & & & & & & & & & & & & & & & & & & & & & & & & & & & & & & & & & $\begin{array}{l}m \\
0 \\
0\end{array}$ & & & \\
\hline$\dot{\overline{0}} \stackrel{\Xi}{\bar{y}}$ & & $\begin{array}{l}\infty \\
\text { n } \\
0 \\
\end{array}$ & & & กี & & & & & & 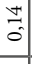 & & & & & & & & & & & & & & & & & & & & & & & & & & & & & & \\
\hline$\dot{\Sigma} \dot{0}$ & & $\begin{array}{l}+1 \\
0 \\
0 \\
0\end{array}$ & & & $\begin{array}{l}3 \\
0 \\
0\end{array}$ & $\begin{array}{l}\hat{2} \\
2 \\
0\end{array}$ & $\begin{array}{l}n \\
0 \\
0\end{array}$ & זे & $\begin{array}{l}\infty \\
\infty \\
0 \\
0\end{array}$ & $\begin{array}{l}R \\
0 \\
0\end{array}$ & $\stackrel{2}{=}$ & $\frac{n}{0}$ & $\begin{array}{l}R \\
0 \\
0 \\
\end{array}$ & & $\begin{array}{l}0 \\
\infty \\
0 \\
\end{array}$ & & $\begin{array}{l}\text { है } \\
- \\
-\end{array}$ & & $\begin{array}{c}\text { m. } \\
0^{2}\end{array}$ & & $\begin{array}{l}+1 \\
+ \\
0 \\
0\end{array}$ & & $\begin{array}{l}\text { f } \\
0 \\
0\end{array}$ & & . & & & & & & 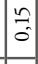 & & के & $\begin{array}{l}0 \\
0 \\
0 \\
0\end{array}$ & \begin{tabular}{l|l} 
& \\
0 & 0 \\
0
\end{tabular} & $\begin{array}{l}n \\
0 \\
0\end{array}$ & $\stackrel{n}{0}$ & & & 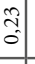 & \\
\hline 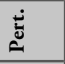 & & & & & & & & & & & & & & & $\begin{array}{l}\circ \\
\infty \\
i \\
i\end{array}$ & $\frac{\infty}{-5}$ & $\begin{array}{l}m \\
0 \\
0\end{array}$ & $\begin{array}{l}\infty \\
\infty \\
\infty \\
0 \\
0\end{array}$ & & & & $\begin{array}{l}\text { ㄴ. } \\
\text { के } \\
0\end{array}$ & & & & & & t: & & & & 영 & $\begin{array}{l}\text { q } \\
\text { o } \\
\end{array}$ & 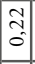 & & $\begin{array}{lll}n & 5 \\
0 & & \\
0 & \end{array}$ & \begin{tabular}{lll}
0 & \multicolumn{2}{c}{} \\
0 & 0 \\
0 & 0
\end{tabular} & $\begin{array}{l}\tilde{n} \\
0 \\
0\end{array}$ & & & $\cong$ \\
\hline 离 & & $\begin{array}{l}\infty \\
\\
\infty\end{array}$ & $\begin{array}{l}\text { ते } \\
\text { ș } \\
\end{array}$ & $\stackrel{\Xi}{m}$ & & & & $\tilde{i}$ & & & & & & & $\begin{array}{l}\text { ते } \\
\text { ते }\end{array}$ & & & & & & & & & & & & & 6 & & & ț & at & & 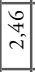 & \begin{tabular}{l|l}
0 & \\
0 & 1 \\
0 & 1 \\
0
\end{tabular} & $\begin{array}{ll}+1 \\
\text { in }\end{array}$ & - & $\begin{array}{l}n \\
\hat{0} \\
0\end{array}$ & $\underset{\substack{\infty \\
\rightarrow}}{-\infty}$ & $\begin{array}{l}\text { Fे } \\
\text { की }\end{array}$ & \\
\hline 它 & 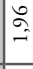 & & $\begin{array}{c}\tilde{m} \\
m \\
m\end{array}$ & & ڤे & $\begin{array}{l}\text { in } \\
\text { in } \\
\end{array}$ & जे & $\stackrel{\infty}{0}$ & $\begin{array}{l} \\
\end{array}$ & 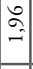 & $\begin{array}{l}\tilde{b} \\
i \\
i\end{array}$ & $\bar{\approx}$ & 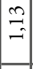 & $\stackrel{I}{=}$ & & & 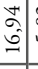 & $\begin{array}{l}0 \\
0 \\
n \\
0\end{array}$ & $\overrightarrow{\vec{f}}$ & \begin{tabular}{l}
\multirow{f}{*}{} \\
\end{tabular} & בె: & 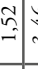 & 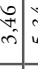 & 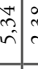 & $\begin{array}{c}\infty \\
\sim \\
i\end{array}$ & 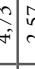 & $\begin{array}{l}n \\
\hat{3}\end{array}$ & & 2 & $\begin{array}{ll}0 \\
0 \\
0 \\
0 & 0 \\
0 & 0\end{array}$ & & & 웅 & 条 & & & $m$ & & के & & \\
\hline 宛 & & & & & & & & & & & & & & & & & & & & & & & & & & & & & & $\stackrel{m}{2}$ & $\begin{array}{l}0 \\
\text { n. } \\
0\end{array}$ & & & 苟 & & & & & & & \\
\hline : & ठ̊ & $\stackrel{8}{\circ}$ & $\bar{\Im}$ & $\begin{array}{l}\overline{0} \\
=\end{array}$ & \begin{tabular}{l}
$\infty$ \\
\multirow{2}{*}{} \\
$\infty$
\end{tabular} & $\begin{array}{l}\approx \\
m\end{array}$ & $\begin{array}{l}\tilde{S} \\
-1 \\
-1\end{array}$ & के & $\because$ & to & $\begin{array}{l}0 \\
\vdots \\
- \\
-\end{array}$ & : & 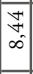 & $\begin{array}{l}n \\
f \\
\forall \\
\forall \\
f\end{array}$ & $\begin{array}{l}4 \\
0\end{array}$ & के & \begin{tabular}{l|l}
0 \\
0 \\
0 \\
0
\end{tabular} & $\hat{n}$ & $\begin{array}{c}\hat{q} \\
-\end{array}$ & î & 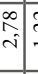 & 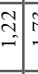 & $\stackrel{5}{=}$ & \begin{tabular}{l|l}
$\hat{0}$ & \\
0 & 0
\end{tabular} & 2 & 0 & $=$ & $: 0$ & 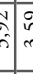 & $=\sqrt{2}$ & $\begin{array}{l}3 \\
0 \\
0\end{array}$ & $\tilde{i}$ & $\begin{array}{l}R \\
0 \\
0\end{array}$ & $\begin{array}{l}m \\
m \\
m\end{array}$ & 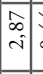 & $\begin{array}{lll}y_{0} \\
0 \\
0\end{array}$ & $\begin{array}{lll}\infty & = \\
-\infty & 0 \\
-0\end{array}$ & $\begin{array}{l}\infty \\
\infty \\
0 \\
0\end{array}$ & $\begin{array}{l}\cong \\
0 \\
0\end{array}$ & $\begin{array}{l}\text { Fे } \\
\text { की }\end{array}$ & $\begin{array}{l}3 \\
- \\
-\end{array}$ \\
\hline$\sum_{\dot{\Delta}}^{\dot{g}}$ & $\vec{\sigma}$ & & $\begin{array}{c}\hat{\lambda} \\
\infty \\
\infty\end{array}$ & $\hat{\imath}$ & $\begin{array}{c}\infty \\
m \\
n^{2}\end{array}$ & $\begin{array}{l}\text { ה. } \\
\text { N }\end{array}$ & 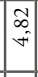 & $\begin{array}{l}\text { i } \\
\text { ¿े } \\
\text { s. }\end{array}$ & $\begin{array}{l}\infty \\
0 \\
0 \\
0\end{array}$ & $\begin{array}{l}\tilde{n} \\
\infty \\
\infty \\
-\end{array}$ & $\begin{array}{l}\mathbb{S} \\
= \\
=\end{array}$ & $\begin{array}{l}\tilde{0} \\
\infty \\
\infty\end{array}$ & $\mid \begin{array}{l}\infty \\
m \\
m \\
m\end{array}$ & 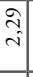 & $\begin{array}{l}\circ \\
\vdots \\
+\end{array}$ & $\begin{array}{l}5 \\
-i\end{array}$ & जे & $\hat{\overbrace{}}$ & $\underset{G}{a}$ & 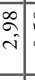 & \begin{tabular}{l|l}
$\infty$ \\
$\stackrel{2}{0}$ \\
0
\end{tabular} & $\begin{array}{l}\text { בี } \\
\cong\end{array}$ & 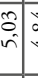 & & 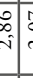 & 6 & 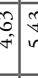 & 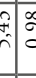 & 8 & 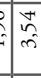 & $\begin{array}{l}\tilde{n} \\
\cdots \\
n\end{array}$ & $\overrightarrow{5}$ & $\begin{array}{l}\infty \\
-\infty \\
-1\end{array}$ & \begin{tabular}{|l} 
aे \\
ñ
\end{tabular} & $\begin{array}{l}\exists \\
0 \\
0\end{array}$ & $\stackrel{\approx}{\approx}$ & \begin{tabular}{l}
$:$ \\
\hdashline
\end{tabular} & 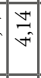 & $\stackrel{0}{\infty}$ & & $\begin{array}{c}\infty \\
0 \\
0 \\
0\end{array}$ \\
\hline$\dot{\dot{g}}$ & $\begin{array}{l}\infty \\
0 \\
0\end{array}$ & & & 离 & $\stackrel{0}{0}$ & $\begin{array}{c}\text { m. } \\
\text { ? }\end{array}$ & $\begin{array}{l}n \\
0 \\
0\end{array}$ & $\stackrel{\infty}{0}$ & & $\frac{\pi}{0}$ & & సิ & & $\overrightarrow{\text { s. }}$ & $\approx$ & $\begin{array}{l}1 \\
0\end{array}$ & $\begin{array}{l}2 \\
2 \\
0 \\
0\end{array}$ & 0 & & \begin{tabular}{ll|}
$\infty$ & \\
0 \\
0 \\
0
\end{tabular} & & 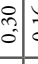 & $\begin{array}{l}0 \\
0 \\
0\end{array}$ & & 0 & $\begin{array}{l} \pm \\
\end{array}$ & & $=$ & 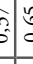 & S. & $\begin{array}{l}n \\
0\end{array}$ & $\begin{array}{l}\text { त̂ } \\
\text { - }\end{array}$ & ले & $\begin{array}{l}{ }_{0} \\
0\end{array}$ & & \begin{tabular}{l|l}
+ & 5 \\
0 & 5
\end{tabular} & $\begin{array}{ll}0 & \infty \\
0 & 0 \\
0 & 0\end{array}$ & 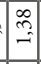 & 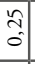 & & \begin{tabular}{l}
$\tilde{y}$ \\
\multirow{2}{*}{} \\
0
\end{tabular} \\
\hline$\stackrel{\substack{\infty \\
\Xi}}{\leftrightarrows}$ & 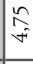 & \begin{tabular}{l}
$\infty$ \\
\multirow{+}{*}{} \\
\hdashline \\
\end{tabular} & 8 & $\begin{array}{l}\text { oे } \\
\text { m }\end{array}$ & $\begin{array}{l}\text { ज́ } \\
\text { mi }\end{array}$ & $\begin{array}{l}\infty \\
\infty \\
\infty \\
\end{array}$ & $\begin{array}{l}+4 \\
0 \\
i \\
\text { in }\end{array}$ & $\begin{array}{l}\text { o } \\
\text { i }\end{array}$ & n. & $\tilde{\omega}$ & ñ & $\stackrel{m}{n}$ & जे & $\begin{array}{l}-5 \\
- \\
- \\
-\end{array}$ & $\begin{array}{l}\circ \\
\infty \\
\sim \\
\end{array}$ & $\begin{array}{l}0 \\
\text { i } \\
\text { in }\end{array}$ & 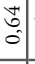 & \begin{tabular}{l} 
fे \\
\multirow{2}{*}{}
\end{tabular} & $\begin{array}{ll} \pm & 1 \\
n & n\end{array}$ & 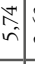 & 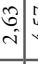 & $\begin{array}{lll}\hat{n} & \\
\sigma^{2} & \end{array}$ & $\begin{array}{l}+4 \\
i \\
i\end{array}$ & ñ & $\begin{array}{l}0 \\
\substack{1 \\
n} \\
n\end{array}$ & \begin{tabular}{c}
$:$ \\
\hdashline \\
$ن$
\end{tabular} & 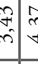 & $=$ & 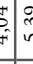 & in & $\begin{array}{l}0 \\
\text { in }\end{array}$ & $\begin{array}{l}\infty \\
\infty \\
n \\
\text { n. }\end{array}$ & $\overrightarrow{2}$ & $\begin{array}{l}m \\
i \\
i\end{array}$ & के & $\begin{array}{ll} & = \\
\Rightarrow & \end{array}$ & $\hat{i}$ & $\begin{array}{l}0 \\
0 \\
i \\
i\end{array}$ & $\begin{array}{l}\text { fi } \\
\text { i }\end{array}$ & \begin{tabular}{l|l|l}
$\infty$ & \\
$\infty$ & \\
$m$ &
\end{tabular} & $\stackrel{2}{=}$ \\
\hline ن & & & & & & & & $n$ & & & & & & & & & & & & & & & & & & & & $\begin{array}{ll}0 \\
0 \\
0 & \\
0 & \end{array}$ & & तु & & & $\begin{array}{l}\infty \\
0 \\
0 \\
\end{array}$ & & & to & & $\stackrel{8}{-}$ & के & के & \\
\hline U & $\begin{array}{l}\hat{\alpha} \\
\infty \\
\text { î }\end{array}$ & \begin{tabular}{l}
\multirow{2}{*}{} \\
$\stackrel{\vec{\lambda}}{A}$ \\
\end{tabular} & $\begin{array}{l}\stackrel{8}{\circ} \\
\dot{+}\end{array}$ & ते & $\begin{array}{l}\overrightarrow{2} \\
\hat{j} \\
\text { ले }\end{array}$ & 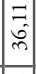 & 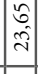 & $\begin{array}{l}\infty \\
\infty \\
0 \\
0\end{array}$ & $\begin{array}{l}1 \\
\text { a } \\
7 \\
\end{array}$ & 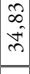 & $\begin{array}{l}4 \\
2 \\
2 \\
\hat{m} \\
\end{array}$ & के & 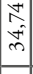 & 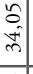 & $\begin{array}{l}\text { fof } \\
\text { } \\
\text { ती }\end{array}$ & 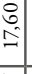 & $\stackrel{\infty}{m}$ & 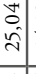 & 足 & 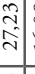 & $\begin{array}{l}\infty \\
0 \\
0 \\
0 \\
0\end{array}$ & mand & 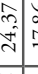 & 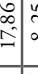 & $\begin{array}{c}0 \\
0 \\
0\end{array}$ & 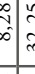 & $\begin{array}{lll} & \\
0 & 0 \\
0 & 0 & \\
0\end{array}$ & tิ & $\begin{array}{c}0 \\
2 \\
2\end{array}$ & $=\begin{array}{c}\hat{\lambda} \\
-i\end{array}$ & $\begin{array}{l}0 \\
2 \\
n= \\
n\end{array}$ & $\mid \begin{array}{l}0 \\
0 \\
3 \\
-1\end{array}$ & & 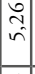 & $\begin{array}{l}\mathcal{D} \\
= \\
=\end{array}$ & 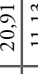 & 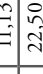 & $\stackrel{n}{2}=$ & 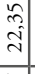 & & \begin{tabular}{|c}
$\hat{A}$ \\
$\infty$ \\
0
\end{tabular} \\
\hline نّ & in & 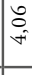 & ज़ & $\begin{array}{l}\infty \\
0 \\
-1 \\
-1\end{array}$ & $\stackrel{+}{\stackrel{2}{*}}$ & $\begin{array}{l}\tilde{3} \\
\text { ปิ }\end{array}$ & 络 & $\begin{array}{l}\text { s. } \\
\text { s. } \\
-7 \\
\end{array}$ & \begin{tabular}{|c|} 
\\
0 \\
m.
\end{tabular} & $\stackrel{\wedge}{\wedge}$ & $\exists$ & $\stackrel{5}{-}$ & 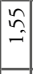 & in & సे & $\begin{array}{l}\hat{n} \\
n^{2}\end{array}$ & $\begin{array}{l}m \\
\text { iे }\end{array}$ & 索 & . & $\begin{array}{l}+1 \\
\vdots \\
0 \\
0\end{array}$ & הี & \begin{tabular}{l|l} 
तิ & \\
$\triangleleft$ &
\end{tabular} & \begin{tabular}{l|l}
0 & 0 \\
$\infty$ & 0 \\
\end{tabular} & 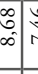 & +2 & $=$ & : & 5 & $\begin{array}{c}0 \\
0\end{array}$ & $\stackrel{n}{n}$ & 2 & 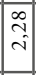 & $\approx$ & $\mid \begin{array}{l}4 \\
\text { in } \\
\text { in } \\
\end{array}$ & $\begin{array}{l}\infty \\
\infty \\
\sigma \\
\forall\end{array}$ & $\bar{s}$ & $\begin{array}{c}\approx \\
-\approx\end{array}$ & $\begin{array}{l}3 \\
i \\
i\end{array}$ & न & 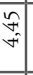 & $\mid$ \\
\hline$\sum^{\frac{m}{j}} \cdot \mathbb{N}$ & $\begin{array}{l}8 \\
\text { î }\end{array}$ & $\begin{array}{l}\bar{\sigma} \\
\tilde{\sim}\end{array}$ & s. & $\frac{2}{2}$ & 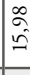 & 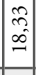 & 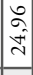 & $\begin{array}{l}\hat{a} \\
\hat{a} \\
\hat{a}\end{array}$ & ה. & $\begin{array}{l}\vec{F} \\
\pm\end{array}$ & $\begin{array}{l}\hat{0} \\
= \\
=\end{array}$ & సิ & \begin{tabular}{|c|} 
\\
7 \\
0 \\
0 \\
\end{tabular} & 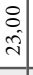 & $\begin{array}{l}\hat{\sim} \\
\vec{\sim}\end{array}$ & $\begin{array}{l}\text { ले } \\
\text { ते }\end{array}$ & $\begin{array}{l}n \\
\hat{m} \\
m\end{array}$ & $\begin{array}{l}a \\
\dot{f} \\
d\end{array}$ & 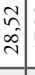 & $\begin{array}{l}1 \\
0 \\
\end{array}$ & ले & 永 & 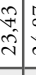 & 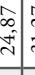 & $\begin{array}{c}\text { A } \\
\text { mi }\end{array}$ & 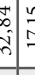 & $=\begin{array}{ll}\infty \\
0 \\
0 \\
0 \\
c\end{array}$ & $\begin{array}{lll}0 \\
0 \\
0 \\
0\end{array}$ & & 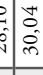 & 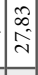 & $\mid \begin{array}{c}\hat{n} \\
\hat{2} \\
\tilde{m}\end{array}$ & $\begin{array}{c}\overrightarrow{0} \\
\infty \\
\infty \\
n\end{array}$ & \begin{tabular}{|l|}
0 \\
0 \\
0 \\
0
\end{tabular} & 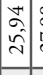 & & $\hat{\imath}$ & $\begin{array}{l}\Omega \\
\bar{\lambda} \\
\bar{\alpha}\end{array}$ & & & 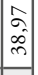 \\
\hline : & 7 & $\checkmark$ & $?$ & 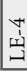 & $n$ & | & 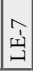 & $\infty$ & $a$ & 굴 & 7 & $\frac{7}{1}$ & $\mid \begin{array}{c}m \\
\overrightarrow{1} \\
\vec{w}\end{array}$ & ज्ञ & 童 & 章 & 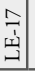 & 文 & के & 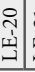 & సิ & 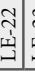 & 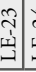 & 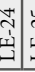 & c) & 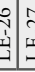 & t. & : & 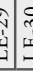 & 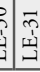 & \begin{tabular}{l}
$\tilde{2}$ \\
$\tilde{1}$ \\
\cline { 1 - 1 }
\end{tabular} & ભి & 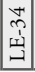 & 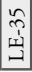 & 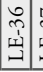 & 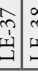 & 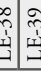 & 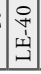 & 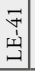 & $\begin{array}{l}7 \\
\text {. } \\
\text { t. } \\
\end{array}$ & 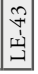 \\
\hline
\end{tabular}




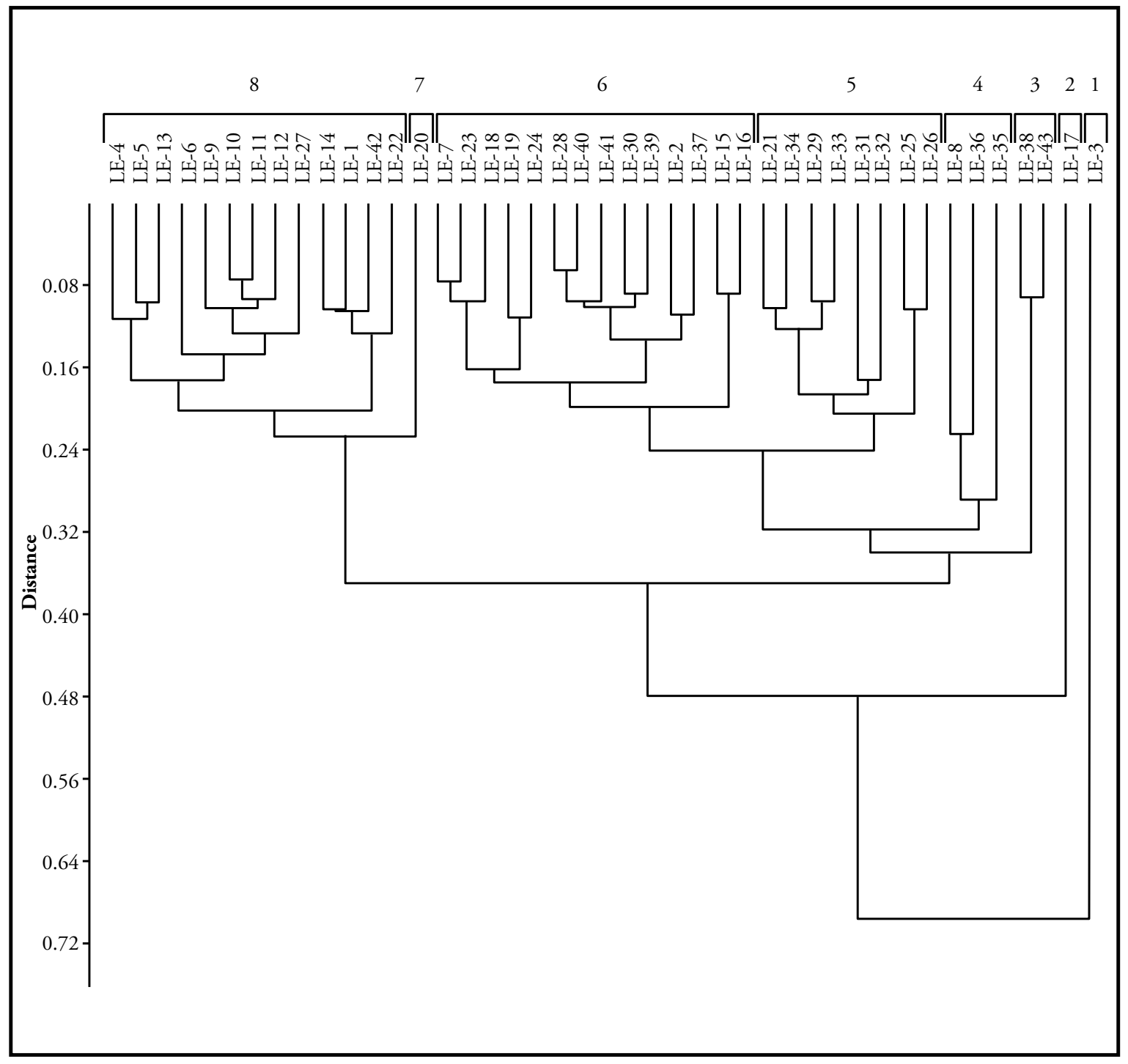

Figura 8. Conglomerado estadístico. 


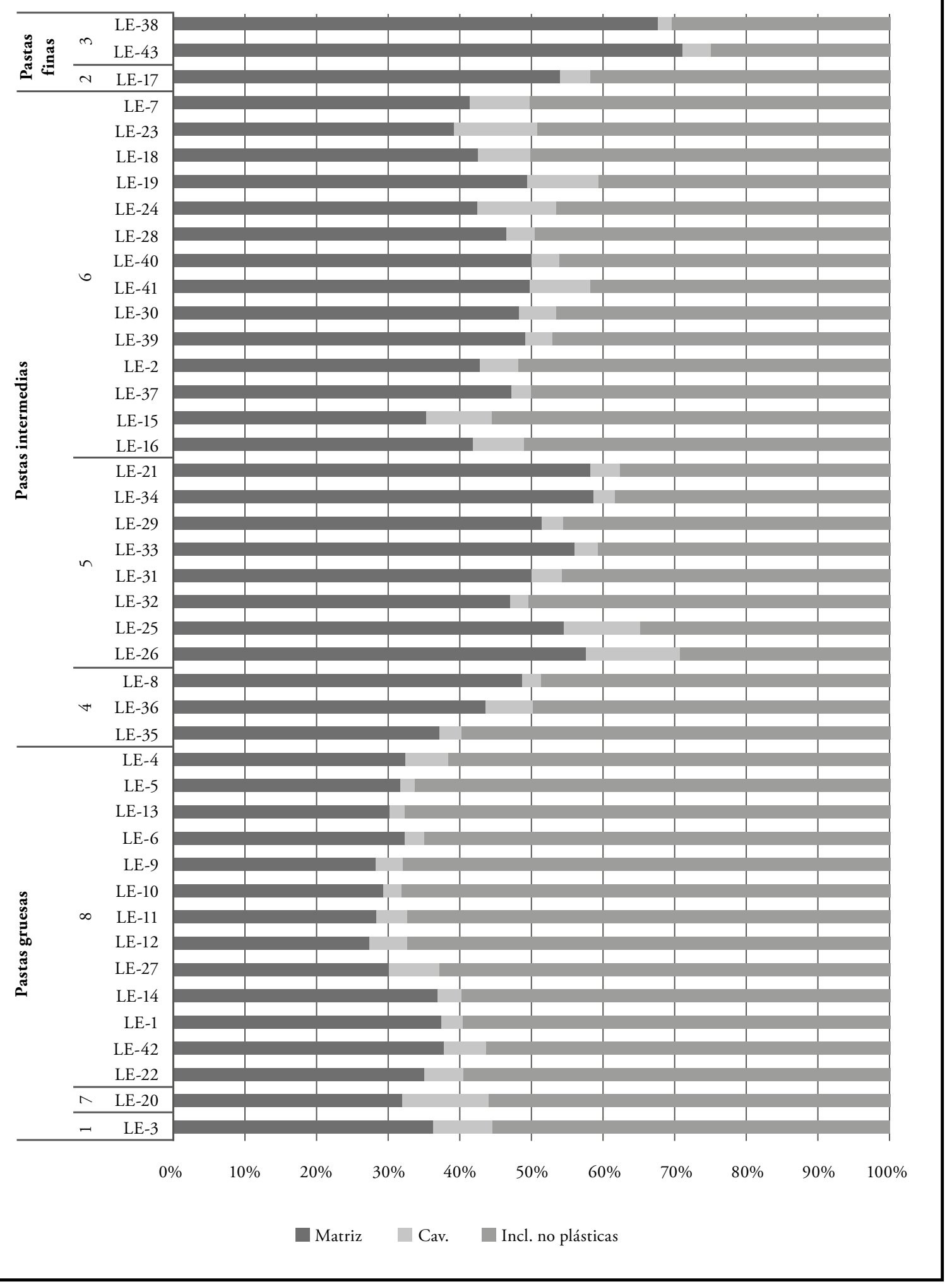

Figura 9. Conformación de cada muestra según la cantidad de matriz, cavidades e inclusiones no plásticas. 


\section{Grupo de las Pastas Gruesas}

Este grupo comprende tres tipos petrográficos: 1,7 y 8 , y agrupa en total 15 muestras. Estos tipo petrográficos, que se localizan en los extremos del conglomerado, son los que mayores diferencias presentan en relación con el resto del conjunto (Tabla 4).

El Tipo petrográfico 1 es el que más alejado se encuentra dentro del dendrograma, es decir, que presenta la mayor diferencia. Está conformado por la muestra LE-3, que corresponde al Tipo 2 Negro Pulido y es una olla con cuello. El porcentaje de matriz es bajo, llegando al 36\%, mientras que las cavidades son escasas $(8,60 \%)$. La matriz es pseudolepidoblástica y algo microgranosa.

La característica sobresaliente es la abundante cantidad de plagioclasa alterada a sericita $(32,26 \%)$. Resaltan las inclusiones de muscovita (11,02\%). También se observaron cuarzos (5,38\%) y feldespatos alterados (4,30\%) (Figura 10).

Las inclusiones no presentan una clara orientación, y tienen una distribución heterogénea, con tamańos que van desde limos gruesos a gránulos (según la escala granulométrica de Udden-Wenthworth (1922)). y formas subrredondeadas en general, con excepción de las micas, que siempre se presentan en forma laminar, y algunos feldespatos alterados de formas redondeadas.

El aspecto de las inclusiones no plásticas y la abundancia de feldespatos alterados a sericita, material muy común en algunas arcillas, indicaría que la mayor parte de las mismas podrían presentarse naturalmente en la arcilla utilizada.

El Tipo petrográfico $7,{ }^{8}$ también está representado por una sola muestra (LE-20), y se corresponde con una escudilla del Tipo 3 Rojo Pulido. La matriz es

8 En este y todos los casos en que una sola muestra se separa en un tipo petrográfico, podría considerarse como un caso aislado. Sin embargo, para mantener una homogeneidad en las denominaciones, igualmente se le llama Tipo petrográfico. Además no debe descartarse que en un futuro, al sumar más muestras, puedan agruparse conjuntamente con aquellas que hoy se presentan como aisladas. escasa $(31,22 \%)$, siendo la pasta con menor porcentaje de matriz de toda la muestra. Tiene estructura pseudolepidoblástica y algo microgranosa, conformada por laminilla de micas y pequeñas inclusiones de cuarzo, menores a $15 \mu \mathrm{m}$, con una distribución no homogénea y sin orientación.

Presenta altos porcentajes de cuarzo $(32,71 \%)$, feldespatos alterados $(8,54 \%)$, así como también cavidades (12,20\%). Se observaron plagioclasas en densidades apreciables $(6,59 \%)$, muscovitas $(3,41 \%)$ y biotita $(2,68 \%)$ así como algunos litoclastos graníticos $(2,68 \%)$.

Las inclusiones no plásticas observadas presentan tamaños que van desde limos gruesos a arenas muy gruesas, mientras que las formas son mayoritariamente subangulares y angulares. La pasta muestra una clara estructura bimodal, a través de la cual se puede proponer el agregado de una arena cuarzosa que, a su vez, ha tenido un alto contenido de feldespatos alterados.

Finalmente, dentro de las pastas gruesas el Tipo petrográfico 8 está integrado por 13 muestras (LE-22, LE-42, LE-1, LE-14, LE-27, LE-12, LE-11, LE-10, LE-9, LE-6, LE-13, LE-5 Y LE-4), 5 pertenecientes al Tipo 1 No decorado, 6 al Tipo 2 Negro Pulido y 3 al Tipo 3 Rojo Pulido.

La matriz tiene porcentajes desde $27,38 \%$ hasta $37,76 \%$, y las cavidades desde 1,83\% hasta 6,96\%. Estas son pseudolepidoblásticas y algo microgranosas, generalmente con biotitas y pequeñas inclusiones de cuarzo en algunos casos.

Este conjunto presenta los mayores contenidos de cuarzo (entre $31,11 \%$ y 45,54\%), además registraron inclusiones de plagioclasa (entre 2,08\% y 7,33\%). El resto de los componentes se presentan en porcentajes variables. También se registraron inclusiones de muscovita (entre 1,49\% y 12,40\%), y biotita (entre $0,60 \%$ y $13,39 \%$ ). Todas las muestras presentan litoclastos graníticos (desde $0,37 \%$ hasta $12,74 \%)$. En todos los casos se identificaron feldespatos alterados o plagioclasas sericitizadas.

Las inclusiones generalmente no se observan orientadas, y la distribución de las mismas en la matriz es 
no homogénea. Los tamaños registrados para las inclusiones no plásticas van generalmente desde limos gruesos a arenas muy gruesas, aunque se registraron casos de gránulos o guijarros. Por su parte, las formas varían entre angulares, subangulares y subrredondeadas. Finalmente, la estructura bimodal detectada en estos casos permite inferir el agregado de un porcentaje bastante alto de arena con importante contenido de cuarzo, y probablemente algunos litoclastos graníticos y feldespatos alterados.

\section{Grupo de Pastas Intermedias}

El grupo de las pastas intermedias reúne tres Tipos petrográficos (4, 5 y 6), y agrupa 25 muestras. Este grupo se dispone en el centro del conglomerado, siendo los últimos en separarse del conjunto general, lo que indica una mayor similitud entre ellos (ver Tabla 4).

El Tipo 4 registra tres muestras (LE-35, LE-36 y LE-8) que presentan porcentajes de matriz que van desde el $37,13 \%$ hasta $45,26 \%$ y cavidades en bajas cantidades $(2,37 \%$ a $6,46 \%)$. Las matrices son, en todos los casos, pseudolepidoblásticas y algo microgranosas, compuestas por pequeñas láminas de mica $\mathrm{y}$ algunos cuarzos.

En cuanto a las inclusiones no plásticas, se observó cuarzo $(6,69 \%$ a $15,46 \%)$, plagioclasas $(2,61 \%$ a $5,68 \%)$ y muscovitas $(9,53 \%$ a $26,07 \%)$. En la muestra LE-35 se detectaron feldespatos $(8,82 \%)$, feldespatos alterados $(8,25 \%)$ y diversos litoclastos alterados difíciles de asignar $(8,82 \%)$, lo cual la diferencia en cierta medida del resto de las muestras. Sin embargo, en todos los casos se observaron biotitas $(3,98 \%$ a $0,47 \%)$, plagioclasa sericitizada $(0,39 \%$ a $3,79 \%)$, rocas graníticas (entre $0,98 \%$ y $3,56 \%)$ y minerales opacos $(0,20 \%$ a $0,95 \%)$, entre otras inclusiones minoritariamente representadas (ver Figura 10).

En algunos casos, en determinados sectores se observó algo de orientación en las inclusiones, las cuales a su vez presentan una distribución bastante homogénea.

Los tamaños de las inclusiones no plásticas van desde limos gruesos a arenas muy gruesas, observando, en casos aislados, algunas inclusiones de tamaños de gránulo. Por su parte, las formas de las inclusiones varían entre subrredondeadas y subangulares, con excepción de las micas que se presentan de formas laminares. Con base en la estructura bimodal observada se puede proponer un agregado de bajos porcentajes de una arena cuarzosa, que posiblemente haya contenido bastante mica.

El Tipo petrográfico 5 reúne ocho muestras (LE-26, LE-25, LE-32, LE-31, LE-33, LE-29, LE-34 y LE21), una perteneciente al Tipo 1 no decorado, 3 al Tipo 2 Negro Pulido, 3 al Tipo 3 Negro Pulido y una se corresponde con Otros (Saujil pulido en líneas). Este tipo petrográfico es bastante similar al anterior, diferenciándose en las cantidades registradas de cada tipo de inclusión. Presento los porcentajes más altos de matriz (entre $46,93 \%$ y $58,60 \%$ ), mayormente psedolepidoblásticas, con excepción de LE-21, que es de apariencia microgranosa. Se registraron cavidades en densidades variables $(2,38 \%$ a $13,29 \%)$.

Asimismo, la cantidad de cuarzo es variable (entre $11,48 \%$ hasta $23,06 \%$ ), como así también las plagioclasas $(1,86 \%$ a $7,51 \%)$, muscovitas $(0,84 \%$ a $7,52 \%)$ y biotitas $(0,425 \%$ a $9,53 \%)$. Es interesante resaltar que, en casi todos los casos, se registró microclino (entre $0,20 \%$ y $1,05 \%$ ). Por otra parte, se destaca la presencia de litoclastos graníticos $(0,23 \%$ a 5,52\%). Finalmente, en cuatro muestras (LE-25, LE-32, LE-31 y LE-29) se observó tiesto molido en porcentajes variables $(3,42 \%$ a $10,46 \%)$.

Las inclusiones en general se presentan algo orientadas, con una distribución no homogénea.

Mientras tanto, los tamaños de las inclusiones registrados pueden ir desde limos gruesos hasta arenas muy gruesas, y las formas son generalmente subangulares aunque se registraron también inclusiones subrredondeadas.

Finalmente, el Tipo 6 (ver Figura 10) reúne 14 muestras (LE-7, LE-23, LE-18, LE-19, LE-24, LE-28, LE-40, LE-41, LE-30, LE-39, LE-2, LE-37, L-15, LE-16), convirtiéndose en el conjunto más numeroso, reflejando con ello el tipo de pasta más común. De estas muestras, dos pertenecen al Tipo 1 No decorado, cinco al Tipo 2 Negro Pulido, cinco al Tipo 3 Rojo Pulido y dos se engloban dentro de Otros. 


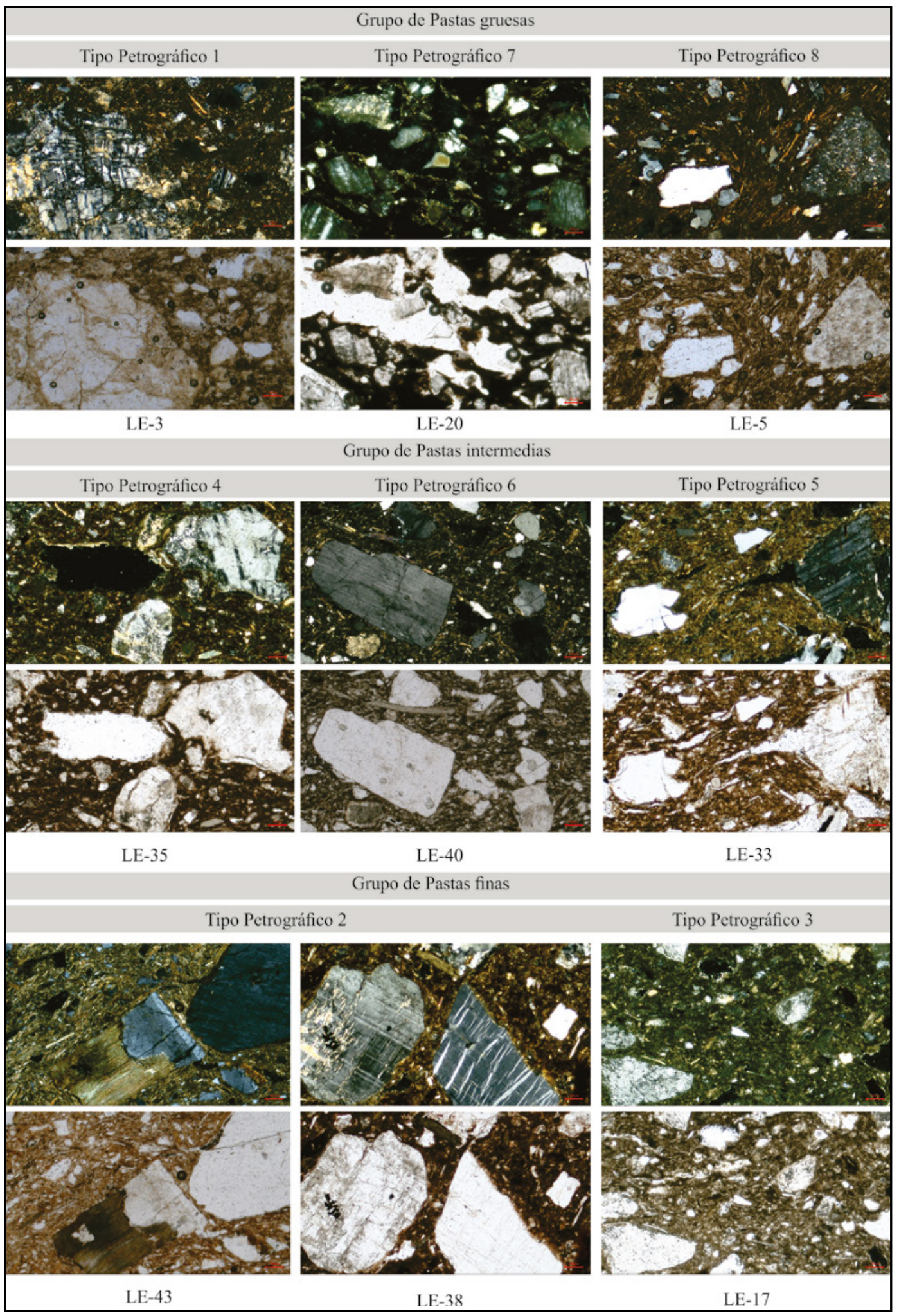

Figura 10. Fotomicrografías de pastas asignadas a los distintos grupos de pastas y tipos petrográficos.

(La referencia de medidas en las imágenes es de $100 \mu \mathrm{m}$ ). 
Este tipo petrográfico se caracteriza por presentar densidades medias de matriz (entre 35,33\% y $50,00 \%)$ y cavidades en densidades variables $(2,45 \%$ a $11,24 \%)$. Las matrices observadas son generalmente pseudolepidoblásticas $(\mathrm{n}=7)$, o pseudolepidoblásticas y algo microgranosas $(n=6)$. Solo una se destaca por ser criptofilitosa (LE-39).

Las inclusiones de cuarzo son muy abundantes $(18,85 \%$ a $31,77 \%)$, solo superadas por las densidades registradas en los Tipos 7 y 8 . También se observaron inclusiones de plagioclasa $(2,56 \%$ a $7,17 \%)$, muscovitas $(1,77 \%$ a $7,28 \%)$ y biotitas $(0,44 \%$ a $5,28 \%)$. La sumatoria de los dos tipos de mica hace que cada muestra pueda alcanzar hasta un $17 \%$.

Además, en todas las muestras se identificaron feldespatos alterados (entre $2,81 \%$ y 7,38\%) o plagioclasa alterada a sericita (entre $0,71 \%$ hasta $6,61 \%$ ). Por otra parte, resulta interesante la presencia, en todos los casos, de rocas de origen granítico (entre 0,36\% hasta 9,31\%). En dos muestras (LE-15 y LE7) se observaron litoclastos volcánicos en cantidades poco significativas (nunca superior al $0,79 \%$ ). También en 10 muestras (LE-16, LE-15, LE-37, LE-2, LE-41, LE-28, LE-24, LE-19, LE-23 Y LE-7) se registró presencia de tiesto molido en muy bajas densidades, nunca superior al 1,58\%.

En general, las inclusiones mayoritarias se presentan sin ningún tipo de orientación $(\mathrm{n}=8)$ o algo orientadas $(n=6)$, con una distribución pobre y tamaños que van desde limos gruesos a arenas muy gruesas. Por su parte, las formas son generalmente subangulares o angulares, encontrándose casos de inclusiones subrredondeadas. La distribución de las inclusiones no es homogénea. La estructura bimodal observada en las muestras podría indicar el agregado, en porcentajes medios a bajos, de una arena de tipo cuarzosa, con componentes graníticos, en donde las micas podrían ser abundantes.

\section{Grupos de las Pastas Finas}

El grupo de las pastas finas presenta una menor cantidad de inclusiones y reúne dos tipos ( 2 y 3 ), los menos numerosos de todo el conjunto. Este grupo se encuentra en un extremo del conglomerado y es el que más difiere dentro del conjunto total después del Tipo petrográfico 1 (ver Tabla 4).

El Tipo petrográfico 2 comprende una sola muestra (LE-17) perteneciente al Tipo 2 Negro Pulido. Presenta altas densidades registradas para la matriz $(54,05 \%)$. Para este caso se observó una matriz pseudolepidoblástica con inclusiones algo orientadas, aunque presenta una distribución no homogénea.

Además muestra los porcentajes más elevados de feldespatos alterados $(23,96 \%)$. El tercer elemento en importancia es la muscovita $(8,47 \%)$, mientras que la biotita se registró en mucha menor cantidad $(1,26 \%)$. También resaltan las inclusiones de cuarzo, aunque no superan el 4,50\%. Mientras tanto, las cavidades se registraron en porcentajes del 4,14\%. Se observó, además, presencia de tiesto molido en bajas cantidades.

El tamaño de las inclusiones mayoritarias puede ir desde arenas muy finas a arenas muy gruesas, y sus formas variar entre subangulares y subrredondeadas.

Se distinguió una estructura bimodal, aunque las formas y las cantidades de feldespatos alterados podrían sugerir que estos, o una gran parte, se podrían encontrar naturalmente en las arcillas utilizadas, aunque seguramente hubo un agregado de arenas, tal vez de una fuente cercana a la de la arcilla. Esto se propone ya que no parece haber una diferencia sustancial entre los elementos característicos de la matriz y aquellos que podrían provenir de un agregado de arenas.

Finalmente, el último Tipo petrográfico definido es el Tipo 3, que comprende dos muestras (LE-43 y LE-38), una perteneciente al Tipo 2 Negro Pulido y otra al Tipo 3 Rojo Pulido. La característica principal se centra en los altos porcentajes de matriz registrados $(67,63 \%$ a $71,20 \%)$; mientras tanto la presencia de cavidades es baja (entre 1,3\% y 3,75\%). Las matrices registradas son pseudolepidoblásticas y algo microgranosas, compuestas por láminas de biotita y algunos pequeńos cuarzos.

Las inclusiones no plásticas más abundantes son los cuarzos $(13,02 \%$ a $17,15 \%)$, seguidos por las plagioclasas $(1,78 \%$ a $4,24 \%)$, luego por las biotitas (entre $2,56 \%$ y $2,89 \%)$, las muscovitas $(1,38 \%$ 
a 3,08\%) y, finalmente, los litoclastos graníticos $(2,56 \%$ a $1,16 \%)$. El resto de las inclusiones detectadas se presentan en bajas cantidades, entre las cuales se encontró microclino y feldespatos con textura pertítica -estos dos con presencia de alteraciones-, además de plagioclasa sericitizada. También es interesante destacar la presencia de tiesto molido en ambas muestras (2,76\% y 0,19\%).

Asimismo, en las inclusiones no plásticas se observa algo de orientación en las inclusiones no plásticas, aunque con una distribución no homogénea. Los tamaños pueden ir desde arenas muy finas a gránulos, y las formas identificadas varían desde subangulares a subrredondeadas, con excepción de las micas, que son laminares.

Se pudo distinguir una estructura bimodal, aunque pareciera que el agregado de arenas se ha dado en bajas cantidades. Estas arenas habrían contenido cuarzo, micas y fragmentos de rocas graníticas.

Tabla 4. Resumen de las características petrográficas.

\begin{tabular}{|c|c|c|c|c|c|c|c|}
\hline Tipo petro. & Tipo de pasta & $\begin{array}{l}\text { Caracterís- } \\
\text { ticas de las } \\
\text { inclusiones } \\
\text { no plásticas }\end{array}$ & $\begin{array}{l}\text { Formas de las } \\
\text { inclusiones } \\
\text { no plásticas }\end{array}$ & $\begin{array}{l}\text { Tamańos de } \\
\text { las inclu- } \\
\text { siones no } \\
\text { plásticas }\end{array}$ & $\begin{array}{l}\text { Porcentajes } \\
\text { y tamańos de } \\
\text { Cavidades }\end{array}$ & Matriz & $\begin{array}{l}\text { Formas de } \\
\text { las vasijas }\end{array}$ \\
\hline Tipo 1 & P.G. & $\begin{array}{l}\text { Mayores } \\
\text { porcentajes } \\
\text { de plagioclasa } \\
\text { alterada a seri- } \\
\text { cita de toda la } \\
\text { muestra. Bajas } \\
\text { cantidades de } \\
\text { matriz y de } \\
\text { cuarzo. }\end{array}$ & Subangulares & $\begin{array}{l}\text { Desde limos } \\
\text { gruesos a grá- } \\
\text { nulos }\end{array}$ & $\begin{array}{l}7,7 \% \\
\text { Medianas }\end{array}$ & $\begin{array}{l}\text { Pseudolepido- } \\
\text { blástica }\end{array}$ & $\begin{array}{l}\text { Olla con } \\
\text { cuello } \\
(n=1)\end{array}$ \\
\hline Tipo 2 & P.F. & $\begin{array}{l}\text { Mayor canti- } \\
\text { dad de feldes- } \\
\text { patos alterados } \\
\text { y muy altas } \\
\text { densidades de } \\
\text { matriz y mus- } \\
\text { covita. Tiesto } \\
\text { molido }\end{array}$ & $\begin{array}{l}\text { Subangulares y } \\
\text { subrredondea- } \\
\text { das. }\end{array}$ & $\begin{array}{l}\text { Desde arenas } \\
\text { muy finas a } \\
\text { arenas muy } \\
\text { gruesas }\end{array}$ & $\begin{array}{l}5,17 \% \\
\text { Medianas }\end{array}$ & $\begin{array}{l}\text { Pseudolepido- } \\
\text { blástica }\end{array}$ & $\begin{array}{l}\text { Olla con } \\
\text { cuello } \\
(n=1)\end{array}$ \\
\hline Tipo 3 & P.F. & $\begin{array}{l}\text { Mayores } \\
\text { porcentajes de } \\
\text { matriz de toda } \\
\text { la muestra. } \\
\text { Cuarzos y pla- } \\
\text { gioclasas. Baja } \\
\text { cantidad tiesto } \\
\text { molido. Menor } \\
\text { densidad de } \\
\text { feldespatos al- } \\
\text { terados de todo } \\
\text { el conjunto. }\end{array}$ & $\begin{array}{l}\text { Subangulares a } \\
\text { subrredondea- } \\
\text { das. }\end{array}$ & $\begin{array}{l}\text { Desde arenas } \\
\text { muy finas a } \\
\text { gránulos }\end{array}$ & \begin{tabular}{|l} 
Entre 2 y \\
$4,79 \%$ \\
Grandes y \\
pequeñas
\end{tabular} & $\begin{array}{l}\text { Pseudolepido- } \\
\text { blásticas y algo } \\
\text { microgranosas }\end{array}$ & $\begin{array}{l}\text { Olla con } \\
\text { cuello }(\mathrm{n}=1), \\
\text { indeterminada } \\
(\mathrm{n}=1)\end{array}$ \\
\hline Tipo 4 & P.I. & $\begin{array}{l}\text { Porcentajes } \\
\text { medios de } \\
\text { matriz, muchas } \\
\text { muscovitas. } \\
\text { Menor canti- } \\
\text { dad de cuarzo } \\
\text { También hay } \\
\text { feldespatos } \\
\text { y litoclastos } \\
\text { alterados }\end{array}$ & $\begin{array}{l}\text { Subrredondea- } \\
\text { da a subangu- } \\
\text { lares. }\end{array}$ & $\begin{array}{l}\text { Desde limos } \\
\text { gruesos a are- } \\
\text { nas muy grue- } \\
\text { sas o gránulos }\end{array}$ & $\begin{array}{l}\text { Entre } 3,21 \text { y } \\
8,23 \% \\
\text { Medianas y } \\
\text { muy grandes }\end{array}$ & $\begin{array}{l}\text { Pseudolepido- } \\
\text { blásticas y algo } \\
\text { microgranosas }\end{array}$ & $\begin{array}{l}\text { Olla con } \\
\text { cuello }(\mathrm{n}=1) \\
\text { tinaja }(\mathrm{n}=1) \text { y } \\
\text { plato }(\mathrm{n}=1)\end{array}$ \\
\hline
\end{tabular}




\begin{tabular}{|c|c|c|c|c|c|c|c|}
\hline Tipo 5 & P.I. & $\begin{array}{l}\text { Altas cantida- } \\
\text { des de matriz } \\
\text { y de cuarzo. } \\
\text { Cavidades en } \\
\text { proporciones } \\
\text { variables. } \\
\text { Microclino } \\
\text { y en algunos } \\
\text { casos tiesto } \\
\text { molido. Menos } \\
\text { proporción de } \\
\text { feldespatos y } \\
\text { plagioclasas } \\
\text { alteradas. }\end{array}$ & Subangulares. & \begin{tabular}{|l} 
Desde \\
limos gruesos \\
a arenas muy \\
gruesas
\end{tabular} & $\begin{array}{l}\text { Entre 3,04 y } \\
17,31 \% \\
\text { Medianas y } \\
\text { muy grandes }\end{array}$ & $\begin{array}{l}\text { Pseudolepido- } \\
\text { blástica }\end{array}$ & $\begin{array}{l}\text { Olla con } \\
\text { cuello }(\mathrm{n}=3), \\
\text { botella }(\mathrm{n}=1), \\
\text { cuenco }(\mathrm{n}=1) \text { e } \\
\text { indetermina- } \\
\text { das }(\mathrm{n}=3) .\end{array}$ \\
\hline Tipo 6 & P.I. & $\begin{array}{l}\text { Matriz en den- } \\
\text { sidades medias, } \\
\text { abundante } \\
\text { cuarzo, altas } \\
\text { cantidades de } \\
\text { mica. Presencia } \\
\text { de feldespatos } \\
\text { alterados. } \\
\text { Algunas rocas } \\
\text { volcánicas. } \\
\text { Tiesto molido. }\end{array}$ & $\begin{array}{l}\text { Subangulares y } \\
\text { angulares }\end{array}$ & \begin{tabular}{|l} 
Desde \\
limos gruesos \\
a arenas muy \\
gruesas
\end{tabular} & $\begin{array}{l}\text { Entre 3,26 y } \\
14,36 \% \\
\text { Medianas y } \\
\text { muy grandes }\end{array}$ & $\begin{array}{l}\text { Pseudolepido- } \\
\text { blásticas y algo } \\
\text { microgranosas }\end{array}$ & $\begin{array}{l}\text { Ollas con } \\
\text { cuello }(\mathrm{n}=3), \\
\text { olla sin } \\
\text { cuello }(\mathrm{n}=1), \\
\text { plato }(\mathrm{n}=1), \\
\text { tinaja }(\mathrm{n}=1), \\
\text { escudillas } \\
(\mathrm{n}=2), \text { cuenco } \\
(\mathrm{n}=1),(\mathrm{n}=1) \text { e } \\
\text { indetermina- } \\
\text { das }(\mathrm{n}=3)\end{array}$ \\
\hline Tipo 7 & P.G. & $\begin{array}{l}\text { Altas cantida- } \\
\text { des de cuarzo. } \\
\text { Feldespatos } \\
\text { alterados y } \\
\text { cavidades en } \\
\text { densidades } \\
\text { relevantes. Me- } \\
\text { nor porcentaje } \\
\text { de matriz en } \\
\text { toda la muestra }\end{array}$ & $\begin{array}{l}\text { Subangulares y } \\
\text { angulares. }\end{array}$ & \begin{tabular}{|l} 
Desde \\
limos gruesos \\
a arenas muy \\
gruesas
\end{tabular} & $\begin{array}{l}16,67 \% \\
\text { Grandes }\end{array}$ & $\begin{array}{l}\text { Pseudolepido- } \\
\text { blástica y algo } \\
\text { microgranosa }\end{array}$ & $\begin{array}{l}\text { Escudilla } \\
(\mathrm{n}=1)\end{array}$ \\
\hline Tipo 8 & P.G. & \begin{tabular}{|l} 
Mayores \\
porcentajes \\
de cuarzo \\
de todo el \\
conjunto, bajas \\
densidades de \\
matriz, y pocos \\
feldespatos y \\
plagioclasas \\
alteradas.
\end{tabular} & $\begin{array}{l}\text { Angulares, } \\
\text { subangulares y } \\
\text { subrredondea- } \\
\text { das. }\end{array}$ & \begin{tabular}{|l} 
Desde \\
limos gruesos \\
a arenas muy \\
gruesas
\end{tabular} & $\begin{array}{l}\text { Entre } 1,45 \text { y } \\
8,91 \% \\
\text { Medianas y } \\
\text { pequeñas }\end{array}$ & $\begin{array}{l}\text { Pseudolepido- } \\
\text { blásticas }\end{array}$ & $\begin{array}{l}\text { Escudillas } \\
(\mathrm{n}=3), \text { plato } \\
(\mathrm{n}=1), \text { taza } \\
(\mathrm{n}=1) \text {, ollas } \\
\text { con cuello } \\
(\mathrm{n}=5) \text {, botella } \\
(\mathrm{n}=2) \text { e in- } \\
\text { determinada } \\
(\mathrm{n}=1) .\end{array}$ \\
\hline
\end{tabular}

\section{Enhebrando relaciones y discutiendo resultados}

Hace aproximadamente unos dos mil años atrás, un grupo de personas se estableció cerca de la desembocadura del río Miriguaca, construyendo un asentamiento a cielo abierto de características particulares. Allí, se habrían llevado a cabo diversas actividades de carácter doméstico, como las inferidas para la Estructura 5 bis, y otras más específicas aún no determinadas, desarrolladas en la Estructura 4. Este sitio, y su asignación cronológica a momentos tempranos del Formativo, nos permite pensar en la existencia de ocupaciones agropastoriles permanentes tempranas en los Sectores Intermedios de la quebrada de Miriguaca. Cabe recordar que, hasta el momento, el sitio formativo más antiguo de la microrregión (Casa Chávez Montículos) con evidencias 
de tipos cerámicos vinculados al norte chileno, se encuentra localizado en el fondo de la cuenca. Por lo tanto, este nuevo hallazgo permitiría retomar la hipótesis de Olivera (1992) de que las aldeas tempranas del Formativo ocupaban sectores de la cuenca, separados por varios kilómetros, manejando parches óptimos del paisaje, que involucraban acceso a zonas con recursos diferenciales (fondo de cuenca, sectores intermedios, quebradas de altura) dentro del modelo de sedentarismo dinámico. Sin lugar a duda, una de las líneas futuras a seguir estará orientada a la identificación del rol de Las Escondidas y los Sectores Intermedios en la consolidación de las sociedades agropastoriles tempranas.

Además, hasta el momento, la información que se tiene sobre la dinámica social del Formativo Temprano en la puna meridional es relativamente escasa. El modelo de sedentarismo dinámico fue un comienzo para entender la complejidad de estas sociedades, pero consideramos que este trabajo, a través del estudio de la cerámica, abre nuevas perspectivas, mostrando amplias redes de movilidad y conexiones identitarias muy estrechas entre el salar de Antofalla y Antofagasta de la Sierra.

Por otra parte, queremos remarcar que este trabajo constituye el primer avance para generar una base de datos petrográficos detallados para este tipo de cerámica y para el área, la que hasta el momento era inexistente. Somos conscientes de que aún hace falta mayor información para poder dar solución a las discusiones vigentes, pero este trabajo es un punto de partida clave para profundizar a futuro estas discusiones. $\mathrm{Al}$ respecto, cabe destacar que están en proceso análisis de activación neutrónica que van a contribuir en este sentido.

Retomando los resultado obtenidos, el material cerámico permitió establecer que, al menos, hubo 74 vasijas diferentes, como cuencos, escudillas, platos, taza, ollas con cuello, ollas sin cuello, tinajas y botellas. Además, se identificó también la elaboración de fichas y de pipas (dos fragmentos).

Respecto al uso, es interesante destacar la baja presencia de ollas con evidencias de utilización, como desgaste, hollín o tizne. Los escasos ejemplos en que se ha observado este tipo de indicadores provienen de la E5 bis. Además, la ausencia, por lo menos hasta el momento, de ollas de gran tamaño destinadas al almacenamiento, podría indicar que no habría sido una actividad común en este sitio. Esta situación también está en consonancia con la portabilidad del repertorio cerámico general, lo cual sería coincidente con actividades agrícolas a baja escala en las que el almacenamiento de excedentes no sería una necesidad primordial. Sin embargo, la presencia de morteros fijos en el sitio podría implicar la realización de actividades de procesamiento de granos $\mathrm{u}$ otros vegetales en el lugar, aunque podrían haber sido realizadas a una escala muy baja y los productos obtenidos consumirse en corto plazo sin la necesidad de almacenarlos.

Entonces, en términos generales, se podría proponer que este conjunto cerámico habría sido resultado de una producción de carácter doméstico, a baja escala y no estandarizada, orientada a cubrir las necesidades diarias de un grupo pequeño de personas. Las características morfológicas y sus dimensiones permiten definir a este conjunto como un equipo cerámico portátil y reducido, que tendría una alta posibilidad de ser transportado. La abundancia de escudillas y formas abiertas conduce a plantear que muchas piezas fueron pensadas para el servicio de alimentos y/o bebidas, mientras que las "botellas" o tinajas habrían sido útiles para el guardado o transporte de líquidos.

En este contexto, y ya que se considera que los objetos ensamblan en sí mismos toda una red de enredos, en la que se interrelacionan aspectos materiales, sociales y simbólicos que adquieren significado en un contexto social particular, entender las características del conjunto de Las Escondidas podría llevar a comprender los contextos en los cuales fueron producidos. De este modo, si se piensa que en esos momentos, los grupos humanos habrían tenido un grado variable de movilidad, basado fundamentalmente en las prácticas pastoriles (sedentarismo dinámico), sería lógico proponer que las vasijas utilizadas estuvieran en consonancia con las actividades y necesidades de los habitantes de este sitio. También, es posible pensar que las actividades específicas y particulares llevadas a cabo en el sitio, especialmente en E4, podrían haber congregado a grupos de personas que se trasladaban desde otros sitios hasta 
Las Escondidas, explicando de esta forma el carácter portátil del equipo cerámico.

Asimismo y aunque la producción cerámica no habría sido estandarizada, sí se observó una marcada tendencia, o más bien una elección tecnológica recurrente, en lo que respecta al acabado de las superficies. La aplicación de un engobe grueso y su posterior pulido, en diferentes grados, es una técnica muy recurrente y que se observa en el $67 \%$ del conjunto total. Este engobe pudo ser de color negro o rojo dependiendo de la cocción a la que fuera sometido, observándose en algunos casos variaciones en el color. Este tratamiento es muy característico del conjunto y le da un sello particular que posibilita individualizarlo fácilmente, y fue esta característica particular la que permitió tender los hilos de la red en la cual estos objetos estuvieron insertos, volcando la mirada hacia otros conjuntos ya estudiados del área, específicamente los que provienen de los sitios Casa Chávez Montículos (Olivera, 1992) y Tebenquiche Chico (Granizo, 2001; Schuster, 2005). Estos sitios presentan ocupaciones asignadas temporalmente al Formativo temprano y se localizan ambos en el departamento de Antofagasta de la Sierra. El primero se ubica en el sector de Fondo de Cuenca, aproximadamente a $10 \mathrm{~km}$ de Las Escondidas, y el segundo, ubicado a la vera del salar de Antofalla, a unos 80 o $90 \mathrm{~km}$ de distancia (Figura 11).

Sin embargo, los datos más interesantes surgen cuando se indaga más allá de lo "visible", ya que aparecen otras hebras del enredo que permiten adentrarse en la enorme red de relaciones de este momento e indagar en los contextos en los cuales tuvieron lugar.

Al respecto, los análisis petrográficos han indicado una relativa homogeneidad en las materias primas utilizadas para la confección del conjunto cerámico de Las Escondidas, que presenta como característica

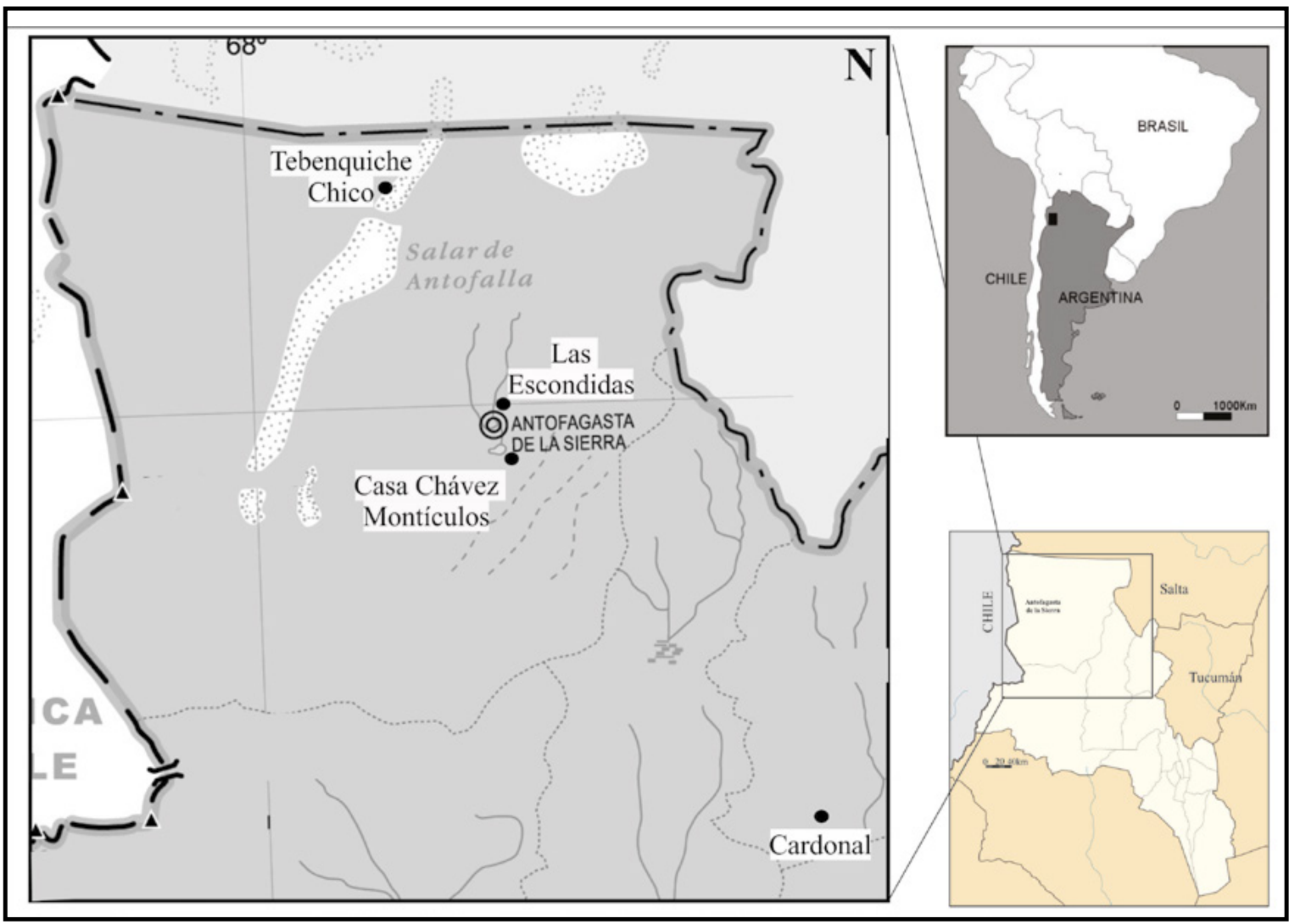

Figura 11. Ubicación de otros sitios que podrían tener cerámica con características semejantes a la de Las Escondidas. 
principal la presencia de inclusiones de feldespatos, plagioclasas y litoclastos alterados, además de otras inclusiones accesorias como cuarzo, micas y algunas rocas de origen granítico. A esto se debe sumar la prácticamente nula presencia de litoclastos volcánicos observados.

Ahora bien, más allá de esta homogeneidad general, se registraron dos tipos petrográficos que difieren del resto básicamente en cuanto a la frecuencia registrada para cada variable analizada: el Tipo 1 y el Tipo 2. El primero, con una alta densidad de inclusiones de plagioclasa alterada a sericita, y el segundo, con altos porcentajes de matriz y feldespatos alterados. Estos dos tipos petrográficos están conformados por solo dos muestras, es decir que son minoritarios dentro del conjunto.

Por otra parte, no parece haber, por lo menos hasta el momento, tipos petrográficos específicos utilizados para formas determinadas. Incluso, en los tipos petrográficos más numerosos (6 y 8) las formas se agrupan indiscriminadamente, incluyendo al menos un ejemplar de cada una de ellas. Esto podría indicar la utilización de una o unas fuentes muy similares para la confección de diferentes formas.

Es interesante remarcar que dentro del Tipo 6 se agruparon las muestras asignadas como Condorhuasi Río Diablo (LE-37) y un fragmento gris pulido con decoración de líneas excisas - posiblemente de estilo Saujil- (LE-39). Estas dos muestras son las que macroscópicamente, en cuanto a sus acabados superficiales, presentan mayor diferenciación con el conjunto general de fragmentos y, sin embargo, se aglomeran estadísticamente dentro de un mismo tipo petrográfico. La variabilidad de formas registradas con este tipo de pasta, sumado a que ninguna forma de inclusión sobresale por encima de otra, podría referir tal vez a una pasta de características "multipropósito", con la cual se podían confeccionar indistintamente diversos tipos de vasijas destinadas a usos indeterminados.

Otro dato interesante que surge de los análisis petrográficos permitió establecer que los tamaños de las inclusiones son bastante homogéneos en toda la muestra, alcanzando en muy pocos casos el tamaño de gránulo, y predominando dimensiones que van desde arenas muy finas a arenas muy gruesas. ${ }^{11}$ Esto podría indicar, en cierta medida, la selección del antiplástico, o bien la utilización de una o unas fuentes en las cuales las inclusiones no plásticas ya estuvieran seleccionadas naturalmente. En cuanto a las formas registradas para las inclusiones, en su mayoría son subangulares a subrredondeadas, lo que lleva a proponer el uso de antiplásticos algo seleccionados y resultantes de sedimentos transportados.

Finalmente, resultó llamativa la homogeneidad de los fondos de pasta o matrices observados, dado que se presentan en su mayoría como pseudolepidoblásticas y, en algunos pocos casos, como algo microgranosas.

Es importante remarcar que la posibilidad de contar con datos sobre la petrografía de las pastas permite describir con certeza los tipos de materiales implicados en la elaboración de pastas. Esta información se convierte en fundamental al brindar la posibilidad de ensayar ciertas correlaciones con las materias primas disponibles a nivel local, principalmente utilizando datos geológicos. Además, las prácticas asociadas al manejo de materias primas representan en sí mismas un medio a través del cual las personas pueden establecer relaciones específicas por medio de los materiales (Albero y Grazia, 2017). Por lo tanto, conocer las características geológicas del área de estudio resulta clave.

En este sentido es oportuno indicar que el paisaje de la microrregión está conformado, prácticamente en su totalidad, por sedimentitas y vulcanitas cenozoicas, que se corresponden con las Formaciones Sijes, Beltrán, Toconquis e Incahuasi (Figura 12).

También las rocas ignimbríticas relacionadas con el colapso del cerro Galán constituyen una característica importante de la geología regional (Aceñolaza, Toselli, y González, 1976; González, 1992; Tchilinguirian, 2008). Estas características volcánicas han sido corroboradas a nivel local a través de análisis petrográficos realizados en arenas obtenidas de la quebrada de Miriguaca. En ellas se observaron, de manera predominante, componentes de origen volcánico en todos los casos, conformados por vulcanitas, andesitas e ignimbritas, entre otros. En ningún caso se identificaron rocas de origen granítico, ni 
feldespatos alterados o plagioclasas sericitizadas, ni tampoco microclinos en la cantidad en que fueron registrados en las muestras de Las Escondidas.

Partiendo de estos datos, resulta interesante advertir que las características petrográficas de las muestras analizadas no se corresponderían, en un principio, con lo descripto para la geología regional, ya que el porcentaje de rocas de origen volcánico identificado es prácticamente nulo. Además, la característica sobresaliente de la composición de estas pastas reside en los feldespatos, plagioclasas y litoclastos, en todos los casos alterados, lo cual le da un sello particular a esta cerámica. La ausencia de rocas de origen volcánico se convirtió en una incógnita que planteó nuevos interrogantes acerca de las características de la producción cerámica de Las Escondidas. La identificación de feldespatos, plagioclasas y litoclastos alterados fue una constante, lo cual junto con la identificación de microclinos permitió plantear la asociación de estos componentes con rocas ígneas félsicas, como granitos, granodioritas y sienitas (Mackenzie y Guilford, 1996). Esta información se convirtió en una línea de evidencia a seguir para ensayar alguna otra vinculación geológica, es decir, otra hebra de la red de enredos que se condensó en estos materiales.

Entonces, ¿podría existir en la región una fuente particular de arcilla que presente las características observadas en las pastas cerámicas?, ¿podrían ser estas piezas elaboradas en otro lugar?, ¿o se habrían trasladado las materias primas?

En este sentido, la ausencia de rocas de origen volcánico en las pastas de Las Escondidas en un contexto en el cual predomina ampliamente este tipo de formaciones geológicas es una incógnita difícil de resolver hasta que no se realicen análisis más específicos para la determinación de procedencia. Sin embargo, la bibliografía referida a la geología de la microrregión y de áreas aledañas ha permitido avanzar en el abordaje de esta problemática.

Los datos referidos a la geografía del departamento Antofagasta de la Sierra, principalmente volcados en las cartas geológicas confeccionadas por el Segemar (Hoja geológica 2569-IV) y su correspondiente descripción, han permitido tener un primer panorama sobre las características geológicas (Seggiaro,
Becchio, Pereyra y Martínez, 2007). Aflorando al norte y sur de la quebrada de Caballo Muerto y al este del salar de Archibarca, en la microrregión del salar de Antofalla, a aproximadamente $80-90 \mathrm{~km}$ de Antofagasta de la Sierra, se encuentra la formación "Granito Archibarca" (ver Figura 12).

Esta formación está compuesta esencialmente por granodioritas, monzogranitos y, en menor proporción, por tonalitas. Los monzogranitos están formados por microclino, ortoclasa, cuarzo, oligoclasa y biotita; además presenta una fuerte alteración a caolín y sericita, principalmente en los feldespatos. Los feldespatos potásicos son los componentes más abundantes, con texturas pertíticas en parches y cordones, mirmequítica y gráfica. El cuarzo es xenomórfico con extinción ondulosa, mientras que la biotita es escasa y está parcialmente alterada a cloritas. Las granodioritas están integradas por plagioclasa, ortoclasa, cuarzo y biotita. La plagioclasa es el mineral más abundante, y se encuentra alterada a sericita y caolín.

Esta descripción del "Granito Archibarca" es muy similar a las inclusiones no plásticas registradas en las muestras de Las Escondidas. Con esto no se pretende afirmar que las arcillas utilizadas para la elaboración de este conjunto provengan directamente de ese lugar, pero podría existir la posibilidad de que algún curso de agua, activo o no en la actualidad, haya arrastrado componentes de esta formación y depositado en una fuente potencial de arcilla, lo cual podría estar respaldado por las formas observadas en las inclusiones relacionadas con sedimentos transportados (ver Figura 12). Esto constituye la punta de un ovillo que deberá hilvanarse con futuros estudios.

De este modo, los análisis petrográficos permitieron obtener información detallada sobre las características de las materias primas utilizadas por los alfareros, indicando el uso de una o varias fuentes muy similares para la confección de las piezas. Las características petrográficas del material de Las Escondidas no presentan una clara correlación con la geología local, aunque podrían asemejarse al "Granito Archibarca" (Seggiaro et al., 2007).

Fueron estas características, sumadas a las mencionadas anteriormente, las que llevaron a indagar en 


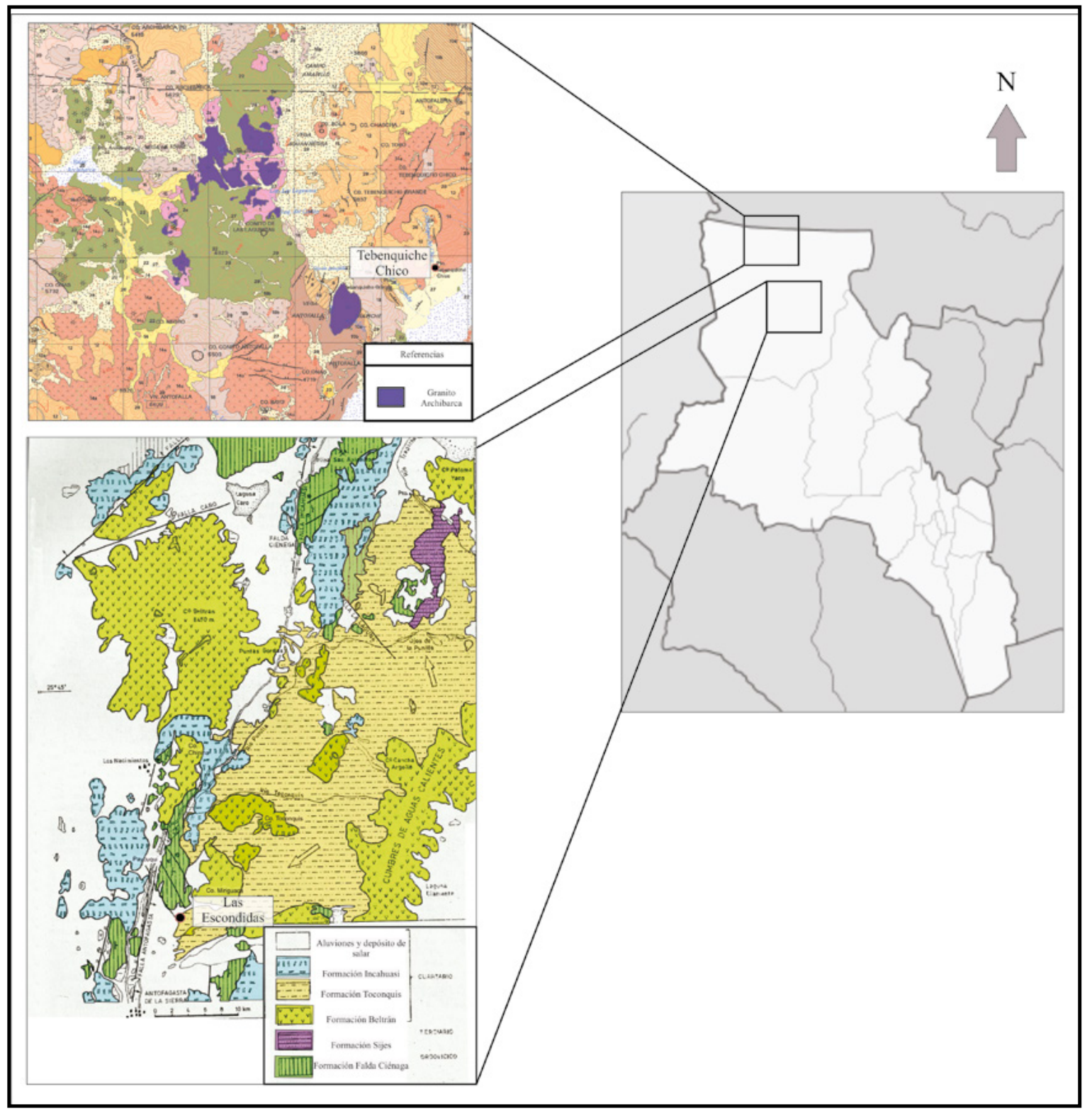

Figura 12. Contexto geológico de la microrregión de Antofagasta de la Sierra (abajo) (Seggiaro et al., 2007) y del área del salar de Antofalla (arriba) (Aceñolaza et al., 1976).

los trabajos realizados sobre la cerámica de Tebenquiche Chico (Granizo, 2001; Schuster, 2005). En primer lugar, las similitudes estilísticas ya mencionadas se ponen de manifiesto cuando se remite a los grupos definidos por Granizo (2001), específicamente aquellos llamados Cerámica 8 y Cerámica 39, provenientes de la ocupación más temprana de este sitio, la cual sería prácticamente contemporánea con la de Las Escondidas.
$\mathrm{Al}$ respecto, la Cerámica 8 ha sido definida como un conjunto de cerámica muy similar a la alfarería San Pedro Negro Pulido, pero posiblemente de manufactura local. Este grupo cerámico presentaría un repertorio amplio de formas y tamańos, e incluso se señala que, con las mismas características técnicas, se realizaban desde vasijas muy pequeñas a otras de gran tamaño. Este tipo de cerámica es el grupo más numeroso en Tebenquiche (Granizo, 2001). 
Posteriormente se realizaron estudios petrográficos sobre muestras de este tipo de cerámica. Así, Schuster (2005) describe dos muestras asignadas a este grupo, que se caracterizan por presentar un alto contenido de feldespatos alterados a minerales arcillosos, plagioclasas y fragmentos de roca muy alterados.

Luego, el grupo llamado Cerámica 39 fue propuesto como de proveniencia alóctona atacameña y se correspondería con aquella cerámica definida como San Pedro Negro Pulido (Granizo, 2001). Esta cerámica fue descripta por Schuster (2005) como compuesta por plagioclasas, cuarzo, biotita, feldespatos potásicos alterados y fragmentos de roca muy alterados, que no pudieron ser determinados. Basados en estas descripciones, no se puede apreciar una diferencia marcada entre la composición de ambos tipos de cerámica, por lo cual no está claro por qué a partir de los datos petrográficos se seguiría manteniendo la idea de procedencias diferentes para ambos tipos definidos.

En términos generales, y a pesar de que no se cuenta con un tratamiento estadístico de los datos petrográficos de Tebenquiche y la profundidad de los análisis es muy diferente a la realizada en Las Escondidas, las similitudes en los componentes de las pastas de ambos sitios son muy sugestivas.

Esta hebra del enredo permitió seguir indagando en otros conjuntos analizados previamente. Así, es interesante destacar las observaciones realizadas por Pereyra Domingorena (2010), quien describe para el valle del Cajón un cuello de un recipiente gris restringido de contorno compuesto, que corresponde al soporte para la representación de un rostro zoomorfo realizado a partir del modelado y la incisión. Este fragmento fue asignado al tipo cerámico Gris Pulido Inciso y Modelado de la Fase Chimpa, la cual ha sido ubicada temporalmente entre el 100 y el 450 DC (Scattolin et al., 2007), por lo tanto, correspondería a un momento bastante temprano sincrónico a otros sitios ya mencionados (Las Escondidas y Tebenquiche). Según el autor, el motivo modelado es similar a la decoración del recipiente encontrado por Haber en el sitio Tebenquiche Chico 1 (Haber, 1999).

La pasta de esta pieza fue considerada como única dentro del conjunto analizado, ya que presenta mi- crolaminillas de biotita y muscovita, microcristales de cuarzo y feldespato potásico fuertemente alterado en su pasta. Así, se propuso una producción alóctona al área del Cajón y se postula una posible vinculación con la puna catamarqueña (Pereyra Domingorena, 2010).

Basados en estas descripciones, la pasta presentada por Pereyra Domingorena (2010) resulta bastante similar a las observadas para Tebenquiche y para Las Escondidas, aunque en este último sitio no se ha encontrado este tipo de representaciones modeladas.

Partiendo de estos datos, y debido a que históricamente se ha asociado la cerámica Negro o Rojo Pulida de la puna meridional con aquella producida en el norte de Chile, resulta interesante comparar los resultados petrográficos obtenidos con los datos existentes para este último. Para esto se contó con los trabajos llevados adelante por Stovel, Cremonte y Echenique (2016), quienes analizaron las pastas cerámicas provenientes de enterratorios y casas de sitios ubicados en San Pedro y en las cercanías del valle superior del río Loa en Chile asignadas al Período Medio (entre 500 - $900 \mathrm{AD}$ ).

En las pastas examinadas, identificaron una predominancia de ignimbritas y rocas volcánicas, a través de lo cual se propuso una fuerte correspondencia con la geología regional que rodea a San Pedro, reflejando la explotación de recursos locales. Estos datos mineralógicos, sumados a los tratamientos superficiales y a la porosidad apuntan, según las autoras, a una homogeneidad mineralógica y tecnológica distintiva.

Esta descripción refleja una característica particular y específica de esta cerámica, que no se corresponde con las descriptas en esta ocasión para la puna meridional argentina. A pesar de que este conjunto no se corresponda con exactitud cronológica al de Las Escondidas, sí permite generar un panorama sobre las características de la producción local en esa área. Entonces, aunque las características visuales o estilísticas de estas cerámicas particulares sean similares, las materias primas utilizadas no fueron las mismas, o por lo menos no parecen provenir del mismo lugar.

Todos los datos vertidos hasta el momento permiten vislumbrar que las redes de relaciones tejidas 
sobre estos objetos particulares son más complejas de lo que podría parecer en un principio. La utilización de materias primas muy similares para confeccionar un tipo de cerámica particular, identificada en distintos lugares de la provincia de Catamarca, implicaría, tal vez, modos de hacer semejantes o compartidos que llevan a pensar en la existencia de profundas redes de relaciones en las que circulaba una cerámica o una materia prima particular, en conjunto con los conocimientos, saberes y significados asociados a ella.

Así, es posible entrever cómo los objetos son los nodos de la red y en ellos se ven condensadas innumerables relaciones que implican lo material, lo social y seguramente lo simbólico.

\section{Consideraciones finales}

A lo largo de este trabajo se ha intentado indagar en las redes de relaciones que se tejen en y sobre los objetos cerámicos de Las Escondidas. Es así como la apariencia externa y las materias primas usadas para la confección de estas vasijas llevaron a proponer conexiones con otros objetos, personas y materiales, uniendo en una misma red la microrregión de Antofagasta de la Sierra con Antofalla y los valles mesotermales. Esta situación sería muy similar a la observada para la obsidiana procedente de la fuente Ona-Las Cuevas, localizada a la vera del salar de Antofalla, y que es encontrada en sitios de Antofagasta de la Sierra (p.e., Las Escondidas o Casa Chávez) y también en el valle del Cajón (Escola, Hocsman y Babot, 2016; Yacobaccio, Escola, Lazzari y Pereyra, 2002; Yacobaccio, Escola, Pereyra, Lazzari y Glascock, 2004).

La existencia de semejanzas entre las pastas de Las Escondidas, Tebenquiche y el valle del Cajón, observadas en las descripciones disponibles y en la comparación visual con fotomicrografías podría sugerir un mismo origen para estas piezas, o la utilización de una misma fuente de materias primas para su elaboración. Tal vez este tipo de materia prima haya contado con ciertas características tecnológicas, sociales o simbólicas específicas. La localización de esta fuente podría estar en relación con la del Granito Archibarca, tanto en sus inmediaciones como dispersadas a mayores distancias por medio de la acción del viento o del agua. También se podría considerar el traslado de determinadas materias primas para confeccionar un tipo de cerámica particular. Por otra parte, se podría pensar en la existencia de amplias redes de intercambio, materializadas en grupos caravaneros que habrían tenido una amplia esfera de acción entre la puna y los valles. En este marco, se habrían trasladado bienes desde un lugar hacia otro, entre los que podrían encontrarse distintos tipos de cerámica, una de ellas con particulares características estilísticas y una pasta definida por feldespatos y litoclastos alterados. Entre los mecanismos de interacción a larga distancia también deben mencionarse, además del caravaneo, el traspaso de mano en mano entre vecinos o parientes, los obsequios, el intercambio de bienes específicos (Yacobaccio et al., 2002), el intercambio incorporado (Nielsen, 2006), o bien las redes de parentesco.

En definitiva, contar con una caracterización detallada del material cerámico de Las Escondidas, que implica tanto lo macroscópico como lo microscópico, puso en evidencia la importancia de investigar este tipo de cerámica propiamente puneña. Consideramos que este tipo de alfarería hace a la identidad de la puna meridional, y a la generación de datos acerca de cómo se desenvolvió la dinámica social de las sociedades en los primeros momentos de la era. Así también, el detallado análisis de pastas obliga a pensar en el rol de este tipo específico de materias primas en el entramado social del Formativo temprano en la puna meridional, abriendo nuevos interrogantes sobre la concepción del paisaje, el uso de las fuentes, la obtención de determinados recursos y las prácticas asociadas a su obtención. En conjunto, la información aquí vertida también obliga a repensar el modelo de sedentarismo dinámico referido a la microrregión de Antofagasta de la Sierra, dejando en evidencia la existencia de una movilidad, interacción o relaciones estrechas entre esta y el área de Tebenquiche. Así, queda planteada la necesidad de indagar con mayor profundidad las evidencias disponibles para comprender cómo fueron tejidas las redes de relaciones en ese momento.

En conclusión, abordar el estudio del material cerámico a través de la idea de la red de enredos (sensu Hodder, 2012) y volver la mirada a los objetos, sin perder de vista la cantidad de materiales y relaciones involucrados en ellos, permitió empezar a vislumbrar 
cómo las cosas ensamblan y reúnen relaciones más allá de ellas mismas. Fueron los objetos cerámicos los que permitieron pensar en la existencia de amplias redes de relaciones, dejando en evidencia el enredo en el que se vieron implicados las personas, lugares, materiales y objetos durante el Formativo.

\section{Agradecimientos}

En homenaje a la Dra. Patricia S. Escola†. Quienes tuvimos la oportunidad de trabajar con ella, seguimos aprendiendo de sus enseñanzas y de su pasión por Antofagasta de la Sierra y la arqueología.

Este trabajo ha sido financiado mediante distintos subsidios otorgados por CONICET, FONCYT y UNCA. Además queremos agradecer a Lorena Grana y Natalia Sentinelli por su participación en estos proyectos y su invaluable ayuda durante la excavación del sitio Las Escondidas; a Guillermo de la Fuente por su predisposición en la confección de cortes delgados y en la discusión de algunos resultados, y a Verónica Schuster por brindarnos información sobre sus trabajos en Tebenquiche. También queremos agradecer a Beatriz Cremonte por su apoyo y asesoramiento en el análisis y discusión de los datos.

\section{Referencias citadas}

Aceñolaza, F., Toselli, A. y González, O. (1976). Geología de la región comprendida entre el Salar del Hombre Muerto y Antofagasta de la Sierra, Provincia de Catamarca. Revista de la Asociación Geológica Argentina, XXXI(2), 127-136.

Albero Santacreu, D. y Melis, M. G. (2017). Pottery and regional mobility in southern Sardinia (Italy) during the Early Copper Age: A petrologic approach. Munibe Antropologia-Arkeologia, 68, 179-195.

Alonso, R. y Viramonte, J. (1987). Geología y metalogenia de la Puna. Estudios geológicos, 43, 393-407.

Ambrosetti, J. B. (1904 [1906]). Apuntes sobre la arqueología de la Puna de Atacama. Revista del Museo de La Plata, XXII, 3-30.

Aschero, C. (1988). Pinturas rupestres, actividades y recursos naturales, un encuadre arqueológico. En Yacobaccio,
H., Borrero, L., García, L., Politis, G., Aschero, C. y Bellelli, C. (Eds.). Arqueología Contemporánea Argentina (pp. 109-145). Buenos Aires: Ediciones Búsqueda.

Aschero, C. y Martínez, J. (2001). Técnicas de caza en Antofagasta de la Sierra, Puna Meridional Argentina. Relaciones de la SAA, XXVI, 215-241.

Aschero, C., Escola, E., Hocsman, S. y Martínez, J. (20022004). Recursos líticos en escala microregional. Antofagasta de la Sierra, 1983-2001. Arqueología, 12, 9-36.

Balfet, M., Bertehelot, F. y Monzón, S. (1991). Normas para la descripción de vasijas cerámicas. México: Centre d'Études Mexicaines et Centraméricaines (CEMCA).

Bourdieu, P. (1977). Outline of a Theory of Practice (Nice, R., trans.). Cambridge: Cambridge University Press.

Bourdieu, P. (1997). Razones prácticas. Sobre la teoría de la acción. Barcelona: Editorial Anagrama.

Cremonte, M. B. (1983-1985). Alcances y objetivos de los estudios tecnológicos en la cerámica arqueológica. Anales de Arqueología y Etnología, 38-40, 179-217.

Cremonte, M. B. (1996). Investigaciones Arqueológicas en la Quebrada de la Ciénaga (Dto. Tafí, Tucumán) (Tesis doctoral). Universidad Nacional de La Plata, La Plata, Argentina.

Dobres, M. (1999). Technology's links and chaînes: the processual unfolding of technique and technician. En Dobres, M. y Hoffman, C. (Eds.). The Social Dynamics of Technology. Practice, Politics and World Views (pp. 124-146). Washington y Londres: Smithsonian Institution Press.

Elkin, D. (1996). Arqueozoología de Quebrada Seca 3: Indicadores de subsistencia humana temprana en la Puna Meridional argentina (Tesis doctoral). Universidad de Buenos Aires, Buenos Aires, Argentina. http://catalogosuba.sisbi. uba.ar/vufind/Record/20160331012309265/Details

Escola, P. (2000). Tecnología Litica y Sociedades Agro-pastoriles Tempranas (Tesis doctoral). Universidad de Buenos Aires, FFyL, Buenos Aires, Argentina.

Escola, P. S., López Campeny, S., Martel, A., Romano, A., Hocsman, S. y Somonte, C. (2013). Re-conociendo un paisaje. Prospecciones en la quebrada de Miriguaca (Antofagasta de la Sierra, Catamarca). Andes, 24(2), 397-424. 
Escola, P. S., Hocsman, S. y Babot, M. P. (2016). Moving obsidian: the case of Antofagasta de la Sierra (Southern Argentinean Puna) during the late Middle and Late Holocene. Quaternary International, 422, 109-122.

González, A. R. (1956). La Cultura Condorhuasi del Noroeste Argentino (Apuntes preliminares para su estudio). Runa, 7 (Parte 1), 37-86.

González, O. (1992). Geología de la Puna Austral entre los $25^{\circ} 15^{\prime}$ a $26^{\circ} 30^{\prime}$ de latitud Sur y los 66 $25^{\prime}$ a $68^{\circ} 00^{\prime}$ de longitud Oeste, provincias de Catamarca y Salta, Argentina. Acta Geológica Lilloana, XVII(2), 63-88.

Grana, L. (2013). Arqueología y Paleoambiente: Dinámica Cultural y Cambio Ambiental en Sociedades Complejas de la Puna Meridional Argentina (Tesis doctoral). Universidad de Buenos Aires, FFyL, Buenos Aires, Argentina.

Granizo, M. G. (2001). La cerámica en Tebenquiche Chico (Tesis de grado). Universidad Nacional de Catamarca, Catamarca, Argentina.

Haber, A. (1999). Una arqueología de los oasis puneños. Domesticidad, interacción e identidad en Antofalla, primer y segundo milenio d.C. (Tesis doctoral). Universidad de Buenos Aires, Buenos Aires, Argentina.

Hammer, Ø., Harper, D. A. T. y Ryan, P. D. (2001). PAST: Paleontological statistics software package for education and data analysis. Palaeontologia Electronica, 4(1), 9.

Hodder, I. (2012). Entangled: An archaeology of the relationships between humans and things. Chichester: WileyBlackwell.

Hogg, A., Hua, Q., Blackwell, P. G., Niu, M., Burck, C. E., Guilderson, T. P. y Zimmerman, S. (2013). ShCal 13 Southern hemisphere calibration, 0-50,000 years CAL BP. Radiocarbon, 55(4), 1889-1903.

Korstanje, M. A. (2005). La organización del trabajo en torno a la producción de alimentos en sociedades agropastoriles formativas (Provincia de Catamarca, República Argentina) (Tesis doctoral). Universidad Nacional de Tucumán, Tucumán, Argentina.

Krapovickas, P. (1955). El yacimiento de Tebenquiche (Puna de Atacama). Anales de Arqueología y Etnohistoria, XIV-XV, 53-113.
Latour, B. (1996). Reassembling the social. An introduction to Actor-Network-Theory. Oxford: Oxford University Press.

Lemonnier, P. (1993). Introduction. En Lemonnier, P. (Ed.). Technological choices: Transformation in material cultures since the Neolithic (pp. 1-35). Londres: Routledge.

Mackenzie, N. S. y Guilford, C. (1996). Atlas de petrografia: minerales formadores de rocas en lámina delgada. Zaragoza: Masson, S.A.

Nielsen, A. (2006) Estudios internodales e interacción interregional en los Andes Circumpuneños: teoría, método y ejemplos de aplicación. En Lechtman, H. (Ed.). Esferas de interacción prehistóricas y fronteras nacionales modernas: los Andes sur centrales (pp. 29-69). Lima: IEP-IAR.

Olivera, D. (1986). El Formativo en Antofagasta de la Sierra (Agro-alfarero Temprano): informa de avance de investigación. Ms.

Olivera, D. (1988). La Opción Productiva: apuntes para el análisis de sistemas adaptativos de tipo Formativo del Noroeste Argentino. Precirculados de las Ponencias Científicas a los Simposios del IX Congreso Nacional de Arqueología Argentina (pp. 83-101). Instituto de Ciencias Antropológicas, Universidad de Buenos Aires, Buenos Aires.

Olivera, D. (1991). El Formativo en Antofagasta de la Sierra (Puna Meridional Argentina): análisis de sus posibles relaciones con contextos arqueológicos Agro-alfareros Tempranos del Noroeste Argentino y Norte de Chile. Actas del XI Congreso Nacional de Arqueología Chilena (1988). Tomo II (pp. 61-78). Museo Nacional de Historia Natural. Santiago: Sociedad Chilena de Arqueología.

Olivera, D. (1992). Tecnología y estrategias de adaptación en el Formativo (agro-alfarero temprano) de la Puna Meridional Argentina. Un caso de estudio: Antofagasta de la Sierra (Pcia. de Catamarca, R.A.) (Tesis doctoral). Universidad Nacional de La Plata, La Plata, Argentina.

Olivera, D. (1997). Los primeros pastores de la puna sur Argentina: Una aproximación a través de su cerámica. Revista de Arqueología Americana, 13, 69-112.

Olivera, D. (2001). Sociedades agropastoriles tempranas: El Formativo Inferior del Noroeste Argentino. En Berberián, E. y Nielsen, A. (Eds.). Historia argentina prehispánica. Tomo I (pp. 83-125). Córdoba: Editorial Brujas. 
Olivera, D. (2012). El Formativo en los Andes del Sur: la incorporación de la opción productiva. En De Haro, M. T., Rocchietti, A. M., Runcio, M. A., y Hernández, O. (Eds.). Actas del V coloquio binacional argentino-peruano. Interculturalidad y ciencias: experiencias desde América Latina (((pp. 15-49). Buenos Aires: Instituto Superior del Profesorado Dr. Joaquín Vv. González.

Olivera, D., Tchilinguirian, P. y Grana, L. (2004). Paleoambiente y arqueología en la Puna meridional argentina: archivos ambientales, escalas de análisis y registro arqueológico. Relaciones de la Sociedad Argentina de Antropologia, XXIX, 229-247.

Orton, C., Tyers, P. y Vince, A. (1997). La Cerámica en Arqueología. Barcelona: Crítica.

Pereyra Domingorena, L. (2010). Manufacturas alfareras de las sociedades aldeanas del primer milenio d.C. al sur de los valles Calchaquies (Tesis doctoral). Universidad de Buenos Aires, Buenos Aires, Argentina.

Quinn, P. (2013). Ceramic Petrography: The Interpretation of Archaeological Pottery \& Related Artefacts in Thin Section. Oxford: Archeopress y Gordon House.

Raffino, R. y Cigliano, M. (1973). La Alumbrera: Antofagasta de la Sierra. Un modelo de ecología cultural prehispánica. Relaciones de la SAA, VII, 241-258.

Rice, P. (1987). Pottery Analysis. A Sourcebook. Chicago \& London: University of Chicago Press.

Rye, O. (1988 [1981]). Pottery Technology. Principles and Reconstruction. Manuals on archaeology no 4 . Australian National University. Washington: Taraxacum.

Scattolin, M. C., Pereyra Domingorena, L., Cortés, L., Bugliani, M. F., Calo, C., Izeta, A. y Lazzari, M. (2007). Cardonal: una aldea formativa entre los territorios de valles y puna. Cuadernos, 32, 211-225.

Schuster, V. (2005). Análisis petrográficos de la cerámica de Tebenquiche Chico (Puna de Atacama). Primer y segundo milenios d.C. (Tesis de grado). Universidad Nacional de Rosario, Rosario, Argentina.

Seggiaro, R., Becchio, R., Pereyra, F. y Martínez, L. (2007). Hoja geológica 2569-IV, Antofalla, provincia de Catamarca y Salta. Instituto de Geología y Recursos minerales.
Servicio Geológico Minero Argentino, Boletín 343, Buenos Aires.

Sempé, C. (1977). Caracterización de la Cultura Saujil. Obra del Centenario del Museo de La Plata, vol. 2: Antropología. La Plata: Universidad Nacional de La Plata.

Shepard, A. (1956). Ceramic for the archaeologist. Washington: Carnegie Institution of Washington.

Sinopoli, C. (1991). Approaches to Archaeological Ceramics. Nueva York: Plenum Press.

Stovel, E., Cremonte, M. B. y Echenique, E. (2016). Petrography and PXRF at San Pedro de Atacama, Northern Chile. En Ownby, M. F., Druc, I. C. y Masucci, M. A. (Eds.). Integrative Approaches in Ceramic Petrography (pp. 53-72). Salt Lake City, UT: The University of Utah Press.

Tchilinguirian, P. (2008). Paleoambientes Holocenos en la Puna Austral, Provincia de Catamarca (27ㅇ): Implicancias Geoarqueológicas (Tesis doctoral). Universidad de Buenos Aires, Buenos Aires, Argentina.

Tchilinguirian, P. y Olivera, D. (2010). Evolution and Human Land Management during the Holocene in southern altiplano desert, Argentina (26\%S). En Zrduli, P., Pagliai, M., Kapur, S. y Faz Cano, A. (Eds.). Land Degradation and Desertification: assessment, mitigation and remediation (pp. 591-604). Springer: Amsterdam.

Uribe, R., Santana-Sagredo, F., Maturana, A., Flores, S. y Agüero, C. (2016). San Pedro de Atacama y la cuestión Tiwanaku en el norte de Chile: impresiones a partir de un clásico estudio cerámico y la evidencia bioarqueológica actual (400-1000 D.C.). Chungara. Revista de Antropología Chilena, 48(2), 173-198.

Weisser, W. (1923/1924). Diario de Viaje. VI Expedición Benjamin Muñiz Barreto. Ms.

Wentworth, C. K. (1922). A scale of grade and class terms for clastic sediments. Journal of Geology, 30, 377-392.

Yacobaccio, H., Escola, P., Lazzari, M. y Pereyra, F. (2002). Long distance obsidian traffic in Northwestern Argentina. En Glascock, M. (Ed.). Geochemical Evidence for Long Distance Exchange (pp. 167-203.). Westport: Bergin and Garvey. 
Tejiendo relaciones a través de la cerámica en los primeros momentos de la era en la puna meridional argentina

Yacobaccio, H., Escola, P., Pereyra, F., Lazzari, M. y Glascock, M. (2004). Quest for ancientet routes: obsidian sourcing research in Northewestern Argentina. Journal of Archaeological Science, 31, 193-204.
Zagorodny, N. (2000). Descripción de una técnica expeditiva de análisis cerámico. Contribución Arqueológica, 5, 259-266.

(c) (1) Este es un artículo de acceso abierto bajo licencia Creative Commons Reconocimiento 4.0 Internacional 